\title{
Estimating the economic cost of setting up a nuclear power plant at Rooppur in Bangladesh
}

\author{
Gour Gobinda Goswami ${ }^{1}$. Umama Rahman ${ }^{2} \cdot$ Mehdi Chowdhury $^{3}$
}

Received: 20 July 2021 / Accepted: 11 December 2021 / Published online: 19 January 2022

( ) The Author(s), under exclusive licence to Springer-Verlag GmbH Germany, part of Springer Nature 2022

\begin{abstract}
Bangladesh government is in the final stage of setting up one nuclear power plant with two units at Rooppur, Ishwardi, each having $1200 \mathrm{MW}$ capacity, to be launched in 2023 to meet the energy shortage urgently. The financial cost of the project is the US $\$ 12.65$ billion. The primary purpose of this paper is to calculate the economic cost of setting up this plant by using the estimation method developed by Du and Parsons (2009), MIT (2003; 2009; 2018), and Singh et al. (2018). It has been found that the economic cost is amounted to 9.36 cents $/ \mathrm{kWh}$ for the capacity of $2400 \mathrm{MW}$. In contrast, for a similar plant in Kudankulam, Tamil Nadu, India, the corresponding cost figure is 5.36 cents/kWh for $2000 \mathrm{MW}$. Even though it seems costlier than India, the study suggests that policymakers should prefer nuclear power, as it is cost-competitive, considering the production cost of other electricity facilities. The main advantage of nuclear power is cost-competitive baseload power generation with zero carbon emission. This nuclear power plant (NPP) project is expected to boost the energy sector of Bangladesh by transforming the country from an energy deficit country into an energy surplus country.
\end{abstract}

Keywords Nuclear power plant $\cdot$ Rooppur $\cdot$ Nuclear power $\cdot$ Nuclear energy $\cdot$ Atomic energy $\cdot$ Levelized cost of electricity $($ LCOE $) \cdot$ Cost-benefit analysis $\cdot$ Discounted present value method $\cdot$ Bangladesh $\cdot$ India

Responsible editor: Philippe Garrigues

Highlights

- Bangladesh government is setting up two units of nuclear power plants in Rooppur with $1200 \mathrm{MW}$ capacity each for the first time in its history.

- The total financial cost of this construction has already been estimated to be US $\$ 12.65$ billion.

- This paper attempts to assess the broader economic cost of setting up this plant at Rooppur, Bangladesh, by using the discounted present value method developed by Du and Parsons (2009), MIT (2003; 2009; 2018), and Singh et al. (2018).

- The levelized cost of electricity (LCOE) has been estimated to be 9.36 cents $/ \mathrm{kWh}$, whereas the rate is 5.34 cents $/ \mathrm{kWh}$ for a similar plant of Kudankulam Tamil Nadu, India.

- In terms of Bangladeshi currency, the LCOE is amounted to BDT $7.94 / \mathrm{kWh}$. Hence, if the government can sell the electricity above this price, the project will be economically viable or profitable.

Gour Gobinda Goswami

Umama Rahman

umama.rahman@northsouth.edu

Mehdi Chowdhury

mchowdhury@bournemouth.ac.uk
2 Department of Management, North South University, Plot 15, Block B, Bashundhara, Dhaka 1229, Bangladesh

3 Department of Accounting, Finance, and Economics, Bournemouth University Business School Dorset House Talbot Campus, Fern Barrow, Poole BH12 5BB, UK

1 Department of Economics, North South University, Plot 15, Block B, Bashundhara, Dhaka 1229, Bangladesh 
JEL Classification D61 · Q4

\section{Introduction}

In 2018, Bangladesh fulfilled the eligibility criterion for graduation from least developed country (LDC) list. Bangladesh's government has a target to reach the status of a highincome country by 2041, which will increase the demand for electricity in the industrial sector substantially in years to come (Ministry of Power 2016). Therefore, adequate energy supply in general and specifically electricity supply will be instrumental in ensuring the country's economic progress in the coming decades. Currently, Bangladesh is producing electricity mainly by utilizing natural gas, but the diminution in natural gas production is a significant concern for future electricity supply. Furthermore, the current demand-supply gap in the electricity sector is another major cause of concern. According to the Bangladesh Power Development Board, per capita electricity generation in Bangladesh is 484 $\mathrm{kWh}$ (including captive production), where $90 \%$ (including the off-grid renewables) of the population have access to electricity (Hydrocarbon Unit, Ministry of Power, 2019). However, the World Development Indicator (2019) estimated that $15 \%$ of the population is still deprived of electricity, while all developed countries have ensured $100 \%$ access to electricity. India, our nearest neighbor country, has $95.24 \%$ access to electricity. Therefore, Bangladesh must meet this gap and ensure that $100 \%$ of the population has access to electricity.

In 2017-2018, the growth in electricity production was $19.02 \%$, indicating that Bangladesh is experiencing a rapid increase in electricity production. However, with a rapid rise in economic activity measured by a real GDP growth rate of around 8\%, which is higher than her South Asian counterparts like India and Pakistan, electricity demand has increased concurrently.

The contraction of natural gas, combined with the growing electricity demand, has resulted in a significant thrust to generate electricity from other sources. The Bangladesh government has taken various initiatives for energy diversification and a robust, high-quality power network to maintain an uninterrupted electricity supply. Electricity generation from the nuclear power plant is one of the vital steps of the Government's commitment to high growth and a smooth supply of electricity at a larger scale. Nuclear power offers an environment-friendly baseload power generation. The land requirement for a nuclear power plant is low and does not need natural resources, i.e., coal, natural gas, or oil. It ensures an uninterrupted power supply for a long time with zero carbon emission and with grid stability. Thus, nuclear power is crucial for fuel diversification of electricity production.
Given this advantage, Bangladesh started constructing the first nuclear power plant in Rooppur in November 2017. The plant will have two units, and the first unit is expected to commence electricity supply by 2023 . The second unit is expected to start its operation in 2024. Nuclear power has a very high initial investment cost, with substantial technical complexity and significant technological, market, and regulatory risks. Still, it can supply a large amount of baseload electricity at a low operating cost (Kennedy 2007). The construction and operation cost of a nuclear power plant (NPP) may depend on the type of nuclear reactor used and the fuel used in its reactors (Ramana (2007); Kennedy 2007; Singh et al. 2018). However, the risk associated with NPP is very high, and the safety of waste disposal of NPP is a fundamental concern (Ministry of Power 2016, World Nuclear Association 2018, IAEA, 2018). The waste disposal cost is another essential cost component of an NPP (Ministry of Power 2016; Islam and Khan 2017, \& Harris et al. 2013). Bangladesh government, policymakers, and researchers are actively looking for a mechanism to determine the total cost of nuclear production. As Bangladesh has just started its NPP, she may face different technical complexity, regulatory issues, and required costs to train her technical personnel (Hydrocarbon Unit, Ministry of Power, 2019). Therefore, along with the capital, operating, and waste disposal costs, Bangladesh will also incur external costs. Electricity generation from NPP will be a better option if the cost of electricity production is competitive. Thus, it is vital to analyze the economics of the NPP for Bangladesh for expanding electricity generation through nuclear energy.

It is challenging to conduct a cost-based analysis to examine the economics of NPP and to find whether the cost of production is competitive relative to other types of energy generation. In South Asia, India has the highest number of nuclear electricity plants and in 2016 produced $2.6 \%$ of its electricity from nuclear sources. India has seven established NPPs with twenty-two reactors, and nuclear power is the fifth-largest source of electricity supply in India (World Nuclear Association, 2018b). This study examines the cost of Rooppur units 1 and 2 with India's Kudankulam units 3 and 4, as both of these NPP are under Rustom, a Russian NPP construction firm.

This study examines the economics of NPP using a financial model to estimate the levelized cost of electricity (LCOE) in both countries. Singh et al. (2018) define levelized cost of electricity (LCOE) as the net present value of the project's total cost over the whole life cycle of the plant divided by the discounted quantity of electricity produced over the plant's lifetime. This study utilizes the financial model used by Du and Parsons (2009), MIT (2003), and 
MIT (2009) to estimate the LCOE of Bangladesh in relationship with India, where India is considered as a benchmark. After estimating LCOE, we conduct a sensitivity analysis to reveal how different cost parameters affect the LCOE calculations in the two countries. The input cost parameters are overnight cost, operation, maintenance cost (O\&M cost), decommissioning cost, fuel cost, and financial parameters: tax rate, cost debt, cost depreciation, and weighted average cost of capital.

The research findings suggest that the cost of nuclear power will be competitive in Bangladesh compared to other power generation facilities. Furthermore, it will also be competitive with other countries in the world. Moreover, according to our findings, nuclear power is competitive compared to other electricity generation facilities in India. We found that the economic cost is estimated to be 9.36 cents $/ \mathrm{kWh}$ for the capacity of $2400 \mathrm{MW}$, whereas for a similar plant in Kudankulam, Tamil Nadu, India, the corresponding cost figure is 5.36 cents $/ \mathrm{kWh}$ for $2000 \mathrm{MW}$.

We select a few countries like China, India, Japan, Pakistan, the UK, and the USA and compare them with Bangladesh to look at nuclear energy and other alternative uses as percentages of total energy use. We see that Bangladesh is lying at the lowest level concerning the other six countries, ranging from 2010 to 2014 (Table 1).
Table 1 shows that the USA is the leading country, followed by the UK. However, Japan has drastically reduced its use from 16.66 to $2.22 \%$. The USA and the UK are still maintaining their percentage above $11 \%$ on average. Pakistan leads with above $4 \%$ in South Asia, whereas India has a figure above $2.5 \%$. China has a double percentage figure compared to India. Bangladesh could not even reach the level of $1 \%$. The table shows that Bangladesh can significantly improve its position in nuclear-based energy exploration.

We show the per capita electric power consumption in the same comparative setup in Table 2. The per capita electric power consumption is the lowest in Bangladesh compared to other selected countries. However, the access to electricity as a percentage of the population is above only of Pakistan. The figure is far below the global standard, and Bangladesh is also lagging behind India in this respect.

We report the electricity production of the selected countries in Table 3. Bangladesh lags behind other countries in electricity production from oil, gas, and coal sources (mainly fossil fuel-based production). Furthermore, Bangladesh, India, and Pakistan have an increasing trend of electricity production from oil, gas, and coal sources, whereas China, the USA, and the UK have a diminishing trend in production from fossil fuel-based sources. Meanwhile, hydroelectric
Table 1 Nuclear energy and other alternative use as a percent of total energy use

\begin{tabular}{lrrrrrl}
\hline Country & 2010 & 2011 & 2012 & 2013 & 2014 & 2015 \\
\hline Bangladesh & 0.17 & 0.20 & 0.17 & 0.22 & 0.15 &. \\
China & 3.51 & 3.52 & 4.09 & 4.53 & 5.11 &. \\
India & 2.35 & 2.70 & 2.53 & 2.72 & 2.67 &. \\
Japan & 16.66 & 7.52 & 2.65 & 2.43 & 2.22 & 3.09 \\
Pakistan & 3.68 & 3.92 & 3.74 & 4.00 & 4.03 &. \\
USA & 11.34 & 11.57 & 11.45 & 11.68 & 11.68 & 11.87 \\
UK & 8.83 & 10.81 & 10.91 & 11.43 & 11.58 & 13.12 \\
\hline
\end{tabular}

Source: The World Bank (2020)

Table 2 Per capita electric power consumption and access to electricity as percent of population

\begin{tabular}{|c|c|c|c|c|c|c|c|c|c|c|}
\hline \multirow[t]{2}{*}{ Country } & \multicolumn{5}{|c|}{ Electric power consumption (kWh per capita) } & \multicolumn{5}{|c|}{ Access to electricity ( $\%$ of population) } \\
\hline & 2010 & 2011 & 2012 & 2013 & 2014 & 2014 & 2015 & 2016 & 2017 & 2018 \\
\hline Bangladesh & 247.26 & 265.64 & 283.46 & 301.96 & 320.20 & 62.40 & 73.13 & 75.92 & 88.00 & 85.16 \\
\hline China & 2943.59 & 3298.00 & 3474.99 & 3773.41 & 3927.04 & 100.00 & 100.00 & 100.00 & 100.00 & 100.00 \\
\hline India & 640.39 & 696.84 & 723.24 & 764.20 & 804.51 & 83.53 & 88.00 & 89.67 & 92.60 & 95.24 \\
\hline Japan & 8594.91 & 8099.60 & 7998.35 & 7988.58 & 7819.71 & 100.00 & 100.00 & 100.00 & 100.00 & 100.00 \\
\hline Pakistan & 442.18 & 432.58 & 427.85 & 457.81 & 447.50 & 70.99 & 71.20 & 71.41 & 70.79 & 71.09 \\
\hline USA & $13,395.14$ & $13,247.01$ & $12,966.12$ & $13,006.75$ & $12,997.45$ & 100.00 & 100.00 & 100.00 & 100.00 & 100.00 \\
\hline UK & 5700.86 & 5471.93 & 5449.26 & 5409.63 & 5130.39 & 100.00 & 100.00 & 100.00 & 100.00 & 100.00 \\
\hline
\end{tabular}

Source:The World Bank (2020) 
Table 3 Electricity production from different alternative sources

\begin{tabular}{|c|c|c|c|c|c|}
\hline Country & 2011 & 2012 & 2013 & 2014 & 2015 \\
\hline \multicolumn{6}{|c|}{ Electricity production from oil, gas and coal sources ( $\%$ of total) } \\
\hline Bangladesh & 98.03 & 98.40 & 98.05 & 98.68 & 98.77 \\
\hline China & 81.17 & 77.86 & 77.42 & 74.82 & 72.96 \\
\hline India & 79.63 & 81.29 & 79.72 & 80.90 & 81.89 \\
\hline Japan & 73.83 & 81.15 & 81.60 & 82.79 & 80.26 \\
\hline Pakistan & 64.47 & 64.20 & 64.10 & 63.47 & 63.09 \\
\hline USA & 68.42 & 68.86 & 67.82 & 67.46 & 67.08 \\
\hline UK & 71.07 & 68.47 & 64.59 & 60.97 & 53.18 \\
\hline
\end{tabular}

Electricity production from renewable sources, excluding hydroelectric (\% of total)

$\begin{array}{llllll}\text { Bangladesh } & 0.00 & 0.00 & 0.26 & 0.27 & 0.27 \\ \text { China } & 2.14 & 2.66 & 3.56 & 4.06 & 4.86 \\ \text { India } & 3.95 & 4.64 & 4.96 & 5.17 & 5.36 \\ \text { Japan } & 3.72 & 4.05 & 4.83 & 6.30 & 7.76 \\ \text { Pakistan } & 0.00 & 0.00 & 0.38 & 0.75 & 0.76 \\ \text { USA } & 4.79 & 5.49 & 6.32 & 6.90 & 7.39 \\ \text { UK } & 7.93 & 9.96 & 13.67 & 17.51 & 22.97\end{array}$

Electricity production from hydroelectric sources (\% of total)

$\begin{array}{llllll}\text { Bangladesh } & 1.97 & 1.60 & 1.68 & 1.05 & 0.96 \\ \text { China } & 14.62 & 17.31 & 16.73 & 18.55 & 19.07 \\ \text { India } & 13.36 & 11.09 & 12.39 & 11.08 & 9.98 \\ \text { Japan } & 7.74 & 7.14 & 7.37 & 7.76 & 8.23 \\ \text { Pakistan } & 29.99 & 31.06 & 30.62 & 30.35 & 30.67 \\ \text { USA } & 7.44 & 6.52 & 6.32 & 6.05 & 5.84 \\ \text { UK } & 1.56 & 1.47 & 1.32 & 1.76 & 1.87\end{array}$

Electricity production from nuclear sources (\% of total)

\begin{tabular}{llllll} 
Bangladesh & 0 & 0 & 0 & 0 &. \\
China & 1.84 & 1.95 & 2.05 & 2.34 &. \\
India & 3.00 & 2.93 & 2.87 & 2.79 & $\cdot$ \\
Japan & 9.47 & 1.51 & 0.88 & 0.00 & 0.91 \\
Pakistan & 5.54 & 4.74 & 4.89 & 4.76 &. \\
USA & 18.98 & 18.76 & 19.17 & 19.23 & 19.32 \\
UK & 18.96 & 19.56 & 19.86 & 19.01 & 20.91 \\
\hline
\end{tabular}

Source: The World Bank (2020)

sources of electricity production have decreased for Bangladesh, whereas electricity production from renewable sources increased, but its share is small compared to the overall electricity production. Bangladesh's position in nuclear production is entirely nil at this stage, whereas there is ample opportunity to tap this channel and achieve rapid and environmentally friendly economic growth.

The above analysis shows that Bangladesh is significantly lagging behind other countries in nuclear energy generation. The facts and figures, therefore, justify the endeavor of Bangladesh to develop a nuclear power plant. Even though the policymakers have a guideline about the expected financial cost of setting up NPP at Rooppur, Bangladesh, no economic cost-benefit analysis has so far been conducted. This paper has attempted to fill this gap through a comprehensive economic cost analysis based on the standard LCOE method developed by Du and Parson (2009), MIT (2003; 2009; 2018), and Singh et al. (2018). We use a different method used by Islam and Bhuiyan (2020) in assessing the economic cost of nuclear in Bangladesh. Islam and Bhuiyan (2020) used Financial Analysis of Electric Sector Expansion Plans (FINPLAN) modeling according to International Atomic Energy Agency (IAEA) 2018, to estimate levelized unit electricity cost (LUEC), net present value (NPV), internal rate of return (IRR), and payback period (PBP) for nine different cases.

On the other hand, this current study provides a detailed LCOE estimation model for Bangladesh and Indian NPP. This economic costing will be immensely useful for the energy pricing of Bangladesh for commercial and other purposes and determine whether the pricing is economically viable or not. Therefore, this paper has direct policy implications for cost-effectively designing the energy pricing strategies of the Bangladesh government. Furthermore, the different cost input parameters of Islam and Bhuiyan (2020) are distinct from ours as the model is different. Another unique contribution of our paper is that it includes the external cost of the first establishment of NPP in Bangladesh as an essential key cost parameter where the previous study did not have such cost input parameters. ${ }^{1}$

With this end in view, the study is organized as follows. The "Literature review" section provides a brief literature review; "The model used in the cost calculation" section introduces the model for cost estimation; the "Estimation of the cost parameters of the model" section presents the estimated results of LCOE; the "Interpretation of the cost estimation result" section provides a detailed interpretation of the result; the "Sensitivity test result" section presents a sensitivity analysis; the "Relevance for the estimated cost" section identifies the relevance for the cost estimation, followed by conclusion and policy suggestions in the "Conclusion and policy implications" section.

\section{Literature review}

Historically, nuclear power is not cost-competitive compared to fossil-fuel electricity or renewable electricity. Therefore, until today, the cost is a critical concern in the expansion of nuclear power. However, the cost is more straightforward to quantify than the benefits side, which is expected to occur in the future. Different studies examine the various aspects of the cost of nuclear power to understand the economics of nuclear power. The literature of cost analysis of NPP can be categorized into three groups: the Monte Carlo estimation

\footnotetext{
$\overline{1}$ We are grateful to an anonymous reviewer for suggesting us to add this section in the introductory part for sharpening the focus of the paper.
} 
method; Real option-based analyses, and standard LCOEbased analyses. In this section, we discuss these three lines of materials one after another. Among all the studies, MIT (2003), MIT (2009), MIT (2018), Wealer et al. (2018), Du and Parsons (2009), De Roo and Parsons (2011), Rothwell (2006), Singh et al. (2018) are noteworthy.

\section{Monte Carlo estimation method}

Monte Carlo simulation is a stochastic method in which the same experiment (i.e., several thousand to millions) is repeated. Different pre-defined variables are chosen from a specific range based on an assumed distribution for each trial. To understand NPP economics, some studies used the Monte Carlo estimation method to stimulate NPV or LCOE of the power plant to examine the likelihood of achieving a certain level of NPV or LCOE (Wealer et al., 2018). Based on the Monte Carlo simulation result, the decision can be made whether an NPP will be economically cost-competitive in the long run.

Wealer et al. (2018), using the Monte Carlo method, argue that the NPP was never an economically viable option to produce electricity. Historically, NPP has higher construction costs than its fossil-fuel counterparts, i.e., coal and natural gas. Moreover, it is still not cost-competitive with a new advanced nuclear reactor system either with renewables or fossil-fuel-based electricity. Therefore, they analyze the private investors' perspective on generic Gen III/III + reactors with $1600 \mathrm{MW}$ capacity, based on data from Europe and the USA. The study results suggest that due to a negative NPV and high LCOE, a private investor cannot invest in nuclear power compared to other electricity production options. It is to be noted that this study does not include data from China and Russia due to the unavailability of data in those countries. Thus, Wealer et al. (2018) might have come up with a different finding if they could have added Chinese nuclear electricity production in their Monte Carlo estimation, as Yu et al. (2020) argue that compared to other clean energy options, nuclear power is cost-competitive in China. According to this study, in 2017, the price of nuclear electricity was slightly higher than coal and hydropower in China, whereas it is lower than solar, wind, and biomass. Therefore, adding China to the Monte Carlo simulations may give a different conclusion for nuclear power generation cost.

\section{Real option-based estimation method}

The real option-based analysis uses the option valuation of an asset considering the uncertainties of investment. In NPP, real option-based analysis is used to examine the riskadjusted cost of capital and the net present value taking into account net revenue uncertainties (Rothwell 2006). Real option value analysis can also be helpful to recognize the sensitivity of different fossil fuel prices.

Rothwell (2006) used a real option-based analysis to examine the prospect of a newly established NPP. This study attempted to determine a risk premium based on the net revenue uncertainty. It identifies that the net revenue (revenue before the payment of construction expenditure) is associated with three risks: price risk, output risk, and cost risk in a deregulated electricity market. This study measures the risks and determines how each of the risks individually and jointly influences the risk-adjusted cost of capital. Finally, this study recommends that giving risk premium and contracting can mitigate a newly established NPP's risks and uncertainty.

\section{Levelized cost of electricity (LCOE)-based method}

In addition to the Monte Carlo estimation method and real option-based cost modeling, levelized cost of electricity (LCOE) is the most widely used method to examine the economics of nuclear power. Different studies used LCOEbased cost modeling to understand the economics of nuclear power. Among them, MIT (2003), MIT (2009), MIT (2018), Du and Parsons (2009), De Roo and Parson (2011), and Singh et al. (2018) are noteworthy. In this LCOE based method, the net present value of the total cost of an NPP is calculated, and then it is divided by the total amount of electricity produced over the plant's life span.

MIT (2003) is the first interdisciplinary research in MIT's future nuclear power research, introducing the standard LCOE-based analysis for nuclear power generation. This study introduces a standard and detailed levelized cost (LCOE) model for electricity generation from nuclear power, using different cost parameters. Later, MIT (2009), Du and Parson (2009), and MIT (2018) introduced a new standard in the nuclear cost analysis with a set of updated cost parameters due to change in various cost components. MIT (2003) calculates the LCOE of a hypothetical $1000 \mathrm{MW}$ nuclear power plant, compares it with $1000 \mathrm{MW}$ coal and natural gas power plants, and examines the cost competitiveness of NPPs. The findings suggest that nuclear power is not costcompetitive in a deregulated electricity market than other fossil fuel alternatives. According to this study, the LCOE of nuclear power, coal, and natural gas are 6.7 US Cents/kWh, $4.2 \mathrm{US}$ cents $/ \mathrm{kWh}$, and $3.8 \mathrm{US}$ cents $/ \mathrm{kWh}$, respectively.

MIT(2009) and Du and Parsons (2009) use the same LCOEbased methodology and update all the cost parameters of MIT (2003) based on the change in the cost of construction. MIT (2003) considers the 2002 price level, whereas these two studies use more recent 2007 price levels for the cost components. Overall findings suggest that the LCOE of NPPs increased when the capital cost of construction doubled. 
MIT (2018) attempts to examine the future of nuclear power in decarbonizing the electricity sector. This study exclusively focuses on new generation nuclear reactors and their cost estimation, where MIT (2003) and MIT (2009) focus on pressurized heavy water (PWR)-based technology. It provides several recommendations to improve nuclear power's cost-competitiveness, as due to high-cost constraints, the various benefits of nuclear power are often ignored. It suggested a shift from previous light water reactor or heavy water reactor to new generation IV rector to reduce cost, introduce appropriate $\mathrm{CO} 2$ emission policies that will make nuclear power competitive, and raise public awareness about the benefits of nuclear energy.

De Roo and Parsons (2011) examine the LCOE for three different types of fuel cycle: once through the cycle and twice through the cycle and fast reactor cycle. The findings suggest that LCOE is higher from a once-through fuel cycle from twice through fuel cycle as twice through cycle involves recycling fuel. Thus, recycling cost raises the LCOE as one additional cost parameter is being added with it. Further, they introduce the concept of equilibrium cost for a fast reactor cycle, when "all reactors in a given fuel cycle scheme operate at constant power and that all mass flows have reached an equilibrium." The critical difference between equilibrium cost and LCOE is that the equilibrium cost is calculated concerning the time dimension.

In contrast, LCOE is the average cost of electricity production throughout the lifetime of a plant. Therefore, the equilibrium cost is higher than the LCOE. This is because equilibrium cost has delayed realization of cost, thus including many delayed costs that can be realized with time. Finally, this study is unique regarding the LCOE and equilibrium cost analysis for different fuel cycle processes and clearly distinguishes between LCOE and equilibrium cost.

The above literature focuses on the economics of nuclear power worldwide based on three categories. However, different studies specifically discuss the economics of India's nuclear electricity generation using LCOE estimation. Singh et al. (2018) examine the levelized cost of electricity produced from light water nuclear reactor technology in India. This article considers Indian-specific values for taxes, depreciation, and returns on equity. Furthermore, this study develops alternative scenarios for overnight costs, fuel costs, operation and maintenance (O\&M) costs, cost of debt, discount rate, and return on equity. In addition to that, this article builds a financial model to calculate the levelized cost of electricity based on the present value of total costs and the discounted value of the total quantity of electricity produced over the plant's lifetime. Finally, this study used a once-through cycle and twice-through cycle option for light water technology. According to their findings, these two options will cost 13.93 cents per $\mathrm{kWh}$ and 14.13 cents per $\mathrm{kWh}$, respectively.

In the case of Bangladesh, no such study examines the economics of nuclear power based on any quantitative model with one exception (Islam and Bhuiyan 2020). This is because nuclear power is very new to Bangladesh, and its first nuclear power plant construction is in progress. It is expected that Bangladesh will generate electricity using nuclear power by the year 2023 .

Therefore, it is clear from the studies that the LCOEbased methodology is widely used to examine nuclear power economics. This method is also suitable for a newly built power plant with no data on cost parameters. Thus, this current study chooses this LCOE-based approach to examine Bangladesh's Rooppur Nuclear Plant economics and compares it with India's Kudankulam Power Plant. To the best of the authors' knowledge, no such peer-reviewed work has been done to estimate Nuclear Power Economics in Bangladesh except Islam and Bhuiyan (2020). They used Financial Analysis of Electric Sector Expansion Plans (FINPLAN) modeling according to International Atomic Energy Agency (IAEA) 2018, to estimate levelized unit electricity cost (LUEC), net present value (NPV), internal rate of return (IRR), and payback period (PBP) for nine different cases. According to their study, the levelized cost of electricity ranges from 43.8 to $82.5 \$ / \mathrm{MWh}$ for Rooppur NPP. Some other non-peer-reviewed works such as Khondker and Hossain (2017) conduct financial and economic feasibility studies of the project by considering only one set of optimistic parameters, such as a PCF of $93 \%$, a plant lifetime of 50 - years, and a discount rate of $5 \%$, and assume 3.5 cent/ $\mathrm{kWh}$ LCOE to estimate the different social and economic cost-benefit ratio of the projects. A summary literature table is provided based on different cost estimation methods.

Besides different cost estimation methods, literature focusing on nuclear power plants in developing countries is very limited. In a developing country with a high population density, it is challenging to manage the construction and operation of nuclear power plants. In developing countries, the private sector cannot support nuclear power plants due to high construction costs and safety issues (Lehtonen et al., 2020). It is critical to examine country-specific risk allocation strategies and financing issues. Hickey et al. (2021) examine the four case studies of four countries on nuclear negotiation and their prospective solution to overcome the commercial constraints of construction. These four countries are Turkey, Egypt, Jordan, and United Arab Emirates (UAE). According to their findings, commercially viable financing and fair risk allocation are significant. The state must consider a comprehensive energy mix strategy and state sovereignty due to complex issues of joint venture ownership of NPP. Degrees of control over any nuclear program, the 
balance of power, and the balance of debt and equity are critically important in the political situation in the Middle East. Notably, in the case of Jordan, due to high financial and repayment of the commercial loan with Rustam, Jordan canceled its two 1000 MW VVER nuclear power plant programs (World Nuclear Association 2021). Instead of a big reactor project in 2018, Jordan focused on buying small module reactor (SMR) project. Ramana and Ahmed (2020) identify that SMR may be a better option for Jordan than two large reactors based on financial resources and the smaller grid capacity of Jordan. However, the problem of SMR includes finding multiple suitable locations for multiple SMR, nearby water resources to cool SMR, and higher cost of electricity generation.

Meanwhile, apart from financial competence to establish nuclear power plants, it is also essential to identify the public attitude towards nuclear energy for the future sustainability of NPP in developing countries. In this context, Gupta et al. (2021) examine the public perceptions about nuclear energy in India using a nationwide survey. The result of their multiple regression analysis suggests substantial support for nuclear energy expansion in India. The public perception about the benefits of nuclear energy offsets the potential risks where concerns about energy security and climate change correlate with support for nuclear energy. Similar results can be found in another public perception study among Turkish people. Yildrium \& Gün (2016) found that climate change and environmental concern have a higher significant impact over positive public attitudes on nuclear energy instead of energy security in Turkey. Furthermore, in Pakistan, Mahmood et al. (2020) suggested that nuclear energy may be a cleaner electricity source than other fossil fuel sources if some effective measures are taken. Therefore, in developing countries with high population density and high energy demand, nuclear energy may be a better option to produce electricity despite financial constraints due to energy security, climate change, environmental concern, and positive public perception. ${ }^{2}$

Furthermore, Nuclear power is a topic of enormous debate for energy policymakers. Gupta et al. (2021) argued that nuclear power is a viable option for emission reduction in developing countries where demand is very high compared to the supply. In developing countries, increased energy demand calls for an uninterrupted baseload electricity supply, where renewable energy may not meet that huge demand. Therefore, nuclear energy can ensure reliable, affordable, and ample electricity supply in developing countries with reduced carbon emissions. On the other

\footnotetext{
${ }^{2}$ We are grateful to an anonymous reviewer for bringing up the issue of developing countries with high population density and low geographical space.
}

hand, the drawback of nuclear power is the potential risks of accidents, waste disposal issues, requirements for highly skilled workers for operation, and long-term effects of radiation (Ho et al. 2019). Muellner et al. (2021) argues that the climate change effect of nuclear would be minimal in the long run. According to the existing nuclear plants, including under-construction sites globally, the maximum reduction in greenhouse gas emissions would be $2-3 \%$ (Muellner et al. 2021). However, Davis and Hausman (2016) argue that only one nuclear plant closure in California in 2012 caused an increase in 9 million metric tons $\mathrm{CO} 2$ emission over 1 year. Therefore, given all the backdrops of nuclear power plants considering the baseload energy benefit with zero carbon emission and the calculated LCOE of the current study, we can safely conclude that nuclear power may be a beneficial option for electricity in the case of Bangladesh.

\section{The model used in the cost calculation}

The current paper aims to estimate the economic cost of setting up the NPP in Rooppur. The research utilizes the LCOE by following the methodology of Du and Parsons (2009), MIT $(2003 ; 2009 ; 2018)$, and Singh et al. (2018). However, there is some criticism against the standard levelized costbased study to understand nuclear power economics. The main criticism of LCOE-based methodology is that risks, uncertainties, and externalities are not included in the analysis. Thus, it is hard to get a clear picture of the economics of nuclear power.

The paper utilizes the standard LCOE method despite the shortcomings described above. The reallife data are not available for nuclear power plants in Bangladesh in the context of our current study. Therefore, Monte Carlo estimation or real option-based analysis, i.e., the other two methods discussed in the literature review, is beyond the scope of this study. Thus, we focus on standard levelized cost-based methodology to analyze the economics of NPPs in Bangladesh. The analysis is compared to that of India.

We calculate the LCOE separately for the newly built nuclear plant in Bangladesh and India using the following Model and compare them. Our result of the Model is determined by the set of assumptions around different cost parameters. The paper is unique in estimating the LCOE for Rooppur NPP, units 1 and 2 in Bangladesh, and units 3 and 4 of Kudankulam NPP in India, all of which are currently under construction. ${ }^{3}$

\footnotetext{
${ }^{3}$ Unit 1 and 2 of Kudankulam are operating from 2013 and 2014, respectively.
} 
This study relies on previous studies as some of the cost parameters for the two power plants are unavailable. Thus, this current study assumes various cost parameters based on previous LCOE studies conducted in different countries. Detailed discussions on the assumptions of different cost parameters are given in the estimation sections.

Both projects are under construction, and we assumed a 7-year construction period with a plant life of 60 years for Bangladesh and India. It is consistent with the World Nuclear Association (2008) and Harris et al. (2013), which estimated a global average of the construction period of NPP to be within 5 to 7 years. Note that the first unit of Rooppur NPP started in November 2017 and is expected to start its operation by 2023/2024 (World Nuclear Association 2020). Furthermore, the development of the second unit began in July 2018 and is expected to start its operation by 2024/2025 (World Nuclear Association 2020). On the other hand, Kudankulam units 3 and 4 started their construction in June 2017 and October 2017, respectively, and are expected to start their operation by 2023 (World Nuclear Association 2020). In the case of our study, the target schedule is 6.5 years approximately. Thus, we add 6 months to cover the uncertainties (including the effect of COVID-19) and assume 7 years for the construction period.

LCOE is estimated by using the following equation:

\section{For Bangladesh}

$\mathrm{OM}_{\mathrm{f}} \quad$ Fixed O\&M cost starting from 8 to 67 years as plant life is 60 years.

$\mathrm{OMv} \quad$ Variable O\&M cost starting from 8 to 67 years as plant life is 60 years.

$\mathrm{F}_{\mathrm{t}} \quad$ Fuel cost starting from 8 to 67 years as plant life is 60 years.

$\mathrm{RE}_{\mathrm{t}} \quad$ Return on equity starting from 8 to 67 years as plant life is 60 years.

CDt Cost of debt starting from 8 years and ending at 36 years after the loan cycle ends.

TDt Tax benefit of deprecation of nuclear power plant starting from 8 to 67 years following the schedule of standards of Singh et al. (2018).

DCOM t Decommissioning cost of the nuclear power plant at the 71 st year.

r Discount rate.

Gn Total electricity produced over the life span of the plant starting from 8 years and ending at 67 years.

The key difference between Eq. 1 and Eq. 2 is the inclusion of external cost identified through the variable. In Eq. 1 for Bangladesh LCOE estimation, we added an external cost of USD 180.7 million and discounted that cost over the 7 years construction period. There is a setup cost for constructing the first NPP. This is just a one-off cost, and once the NPP starts operating, there will be regular operation and mainte-

$$
L C O E=\frac{\sum_{T=1}^{7} \frac{K_{t}+I D C}{(1+r)^{t}}+\sum_{T=1}^{7} \frac{E X c}{(1+r)^{t}}+\sum_{8}^{67} \frac{I C C}{(1+r)^{t}}+\sum_{8}^{67} \frac{O M_{f}}{(1+r)^{t}}+\sum_{8}^{67} \frac{O M_{v}}{(1+r)^{t}}+\sum_{8}^{67} \frac{F_{t}}{(1+r)^{t}}+\sum_{8}^{67} \frac{R E_{t}}{(1+r)^{t}}+\sum_{8}^{36} \frac{C D_{t}}{(1+r)^{t}}-\sum_{8}^{23} \frac{T D_{t}}{(1+r)^{t}}+\sum_{71} \frac{D C O M_{t}}{(1+r)^{t}}}{\sum_{8}^{67} \frac{G_{n}}{(1+r)^{t}}}
$$

\section{For India}

$$
L C O E=\left(\sum_{T=1}^{7} \frac{K_{t}+I D C}{(1+r)^{t}}+\sum_{8}^{67} \frac{I C C}{(1+r)^{t}}+\sum_{8}^{67} \frac{O M_{f}}{(1+r)^{t}}+\sum_{8}^{67} \frac{O M_{v}}{(1+r)^{t}}+\sum_{8}^{67} \frac{F_{t}}{(1+r)^{t}}+\sum_{8}^{67} \frac{R E_{t}}{(1+r)^{t}}+\sum_{8}^{36} \frac{C D_{t}}{(1+r)^{t}}-\sum_{8}^{23} \frac{T D_{t}}{(1+r)^{t}}+\sum_{71} \frac{D C O M_{t}}{(1+r)^{t}}\right) / \sum_{8}^{67} \frac{G_{n}}{(1+r)^{t}}
$$

\section{Description of the parameters of the model}

Here, Kt Capital cost of construction; $t=7$ years of the construction period.

EXc External cost during construction; $\mathrm{t}=7$ years of the construction period only applicable in the context of Bangladesh.

IDC Interest payment during construction period; $\mathrm{t}=7$ years of the construction period.

ICC Incremental capital cost starting from 8 to 67 years as plant life is 60 years.

\footnotetext{
4 The above two equations are modified from Singh et al. (2018) and Du and Parsons (2009).
}

nance costs. For India, no such one-off cost is included in the estimation.
The total duration of the model is 67 years, where the first 7 years are considered to be the pre-construction period, and the following 60 years are considered as the plant's operating period. Each cost parameter is associated with each of the periods of the nuclear life cycle. During construction, the two key cost parameters are construction cost and interest payment, and during operation, the key parameters are variable operating cost, discount rate, tax, and depreciation rate. The decommissioning cost of the NPP commences after the end of its operating period. At the decommissioning phase, plant facilities' safety process, disposal, and storage induce cost decommissioning (Singh et al. 2018). We estimate the LCOE for the two countries using the above-mentioned Eqs. 1 and 2. In order to maintain comparability, all the estimations are in the 2010 US dollar value. The evaluation of LCOE is 
greatly influenced by different input cost parameters that are discussed in the following sections. Finally, to remain consistent with other studies, we do not calculate the accident risks or any other factor interrupting the electricity supply during the plant's lifetime.

The method involves a detailed estimation of the cost parameters, which is described in the following section.

\section{Estimation of the cost parameters of the model}

The selection of the appropriate cost parameter will be addressed in the section following our literature review and assumptions made in the previous sections. All the parameters are adjusted with country-specific values. For example, tax rate, discount rate, depreciation, and debt-equity ratios vary between Bangladesh and India. We consider the current fiscal and regulatory environment to determine different parameters for the two countries. Further, we adjust the price level and inflation for the given parameters. Methods for selecting the different cost parameters for LCOE estimation are given below:

\section{Overnight cost}

The overnight cost is a part of the capital cost. It includes construction, system cost, procurement cost, engineering cost, cost of equipment, first fuel load, and other costs (World Nuclear Association 2020). This kind of cost is one of the key cost components of the NPP. The share of overnight cost accounts for a significant portion of the LCOE; thus, estimation of this cost is crucial while determining LCOE (Du and Parsons 2009).

According to the World Nuclear Association (2020), the total capital cost of construction exclusive of interest during construction and cost escalation is 12.65 billion USD for $2400 \mathrm{MW}$ of Rooppur and 6.25 billion USD for 2000 MW Kudankulam units 3 and 4. Therefore, this paper calculates $\$ 5271 / \mathrm{KW}$ for the Rooppur power plant while considering $2400 \mathrm{MW}$ capacity and $\$ 3125 / \mathrm{KW}$ for Kudankulam while considering the 2000 MW capacity of the plant. In the case of India, previous studies use a similar figure for overnight cost estimations. Singh et al. (2018) use overnight cost at $\$ 3000 / \mathrm{KW}$, where Bharadwaj et al. (2008) use a range of \$2000-\$3000/KW. However, this study uses an exact amount rather than an approximation because the overnight cost is derived from real-life data. In the case of Bangladesh, the overnight cost seems significantly higher than most of the studies as Rooppur is the first NPP of Bangladesh. Therefore, it includes the setup cost instead of already established 22 nuclear reactors in India. We use this estimated figure for the base case scenario. However, the study uses a range of overnight costs of \$2500-\$3750/KW for India and \$4217-\$6326/KW in Bangladesh in the sensitivity analysis.

The overnight cost has been distributed based on the construction schedule and discounted with a given rate. The changes in LCOE are directly proportional to the changes in the overnight cost, and these fluctuations are discussed in detail in the following sections.

\section{Interest during construction}

Interest during construction (IDC) is another essential component of our LCOE estimation. This cost represents the interest cost on funds raised to build the plant (such as loan debt or stock equity) (MIT 2018). This cost is incurred during the construction period when there is no operating income. Thus, this cost is included in the capital cost as a financing cost. This cost is also known as "interest during construction" (IDC) or "accumulated funds during construction" (AFD) (MIT 2018). In other words, this is the interest payment on the amount borrowed to finance the capital during the construction period (Singh et al. 2018). Different studies suggest different capital costs as IDC; however, MIT (2018) estimated IDC $20 \%$ of capital cost.

Furthermore, the World Nuclear Association (2020) suggests IDC as $30 \%$ of capital when the construction period is 5 years and increases to $40 \%$ of capital when the construction period is 7 years. On the other hand, Singh et al. (2018) estimate (for an overnight cost of $\$ 2000 / \mathrm{KW}$ ) IDC as US\$324.05 million for a 5-year construction period in India. In addition to that, Bharadwaj et al. (2008) estimate IDC as $20 \%$ of the capital cost for a 5-year construction period, where Bharadwaj et al. (2006) measured 25\% of the capital cost as IDC. However, we have chosen $40 \%$ of capital cost as IDC due to the 7 -year construction period, for India and Bangladesh, following the World Nuclear Association (2020).

\section{Operations and maintenance costs (O\&M)}

Compared to coal, natural gas, and other electricity generation facilities, the advantage of nuclear power is the low cost of O\&M (Du and Parsons 2009). This cost solely depends on the NPP's type of reactor and technology (Singh et al. 2018). Due to the unavailability of data for cost parameters, we modified the O\&M cost used in MIT (2009) and Du and Parsons (2009) input parameters. Unlike Singh et al. (2018), we estimate the fixed and variable operation and maintenance costs separately, following MIT (2003, 2009), Du and Parsons (2009), and MIT (2018). According to our estimation, the fixed operation and maintenance cost is $\$ 92.63 / \mathrm{kW} /$ year, and the variable operation and maintenance cost is $0.69 \mathrm{mills} / \mathrm{kWh}$. According to MIT (2009) and Du and Parsons (2009), these costs were $\$ 56 / \mathrm{kW} /$ year and 0.42 mills, respectively. On the other hand, Singh et al. 
(2018) and Bharadwaj et al. (2006) did not divide the operations and maintenance costs into the fixed and variable parts but instead calculated aggregate operations and maintenance costs.

\section{Fuel cost}

One of the key benefits of an NPP is the low fuel cost compared to other electricity-generating facilities. According to Du and Parsons (2009) and MIT (2009), fuel cost is $0.67 \$ /$ MMBtu, where Singh et al. (2018) calculate this cost at 0.69 cents/kWh. Therefore, following Du and Parsons (2009) and MIT (2009), we collect the 2018 price of uranium from EIA, which is $0.68 \$ / M M B t u$, and use this price to estimate respective LCOE for India and Bangladesh.

\section{Incremental capital cost (ICC)}

Incremental capital cost is calculated as operating cost following MIT (2003, 2009) and De Roo and Person (2009) model. This cost was added with decommissioning costs and discounted over time. In our study, we calculate the incremental cost as $1 \%$ of the overnight cost for India and Bangladesh, following MIT $(2003,2009)$ and Du and Person (2009).

\section{Tax benefit of depreciation}

We assume a 7-year construction schedule with two separate depreciation schedules for the two countries. Depreciation provides a tax shield; thus, calculating the depreciation schedule while estimating the LCOE is essential. MIT $(2003,2009)$ and Du and Parsons (2009) estimate a 15-year modified accelerated cost recovery system (MACRS) depreciation schedule, while this study uses a $10 \%$ salvage value, and the remaining $90 \%$ is distributed throughout the 60 years plant life of the NPP. In the case of Bangladesh, we estimate the rate of depression and schedule following the Bangladesh Power Development Board (2018) and Bangladesh Energy Regulatory Association (2016). Wee calculated a $3.28 \%$ depreciation rate for the first 10 years, and from the 11th year until the 60th year, the remaining $90 \%$ is evenly distributed. ${ }^{5}$ In contrast, in the case of India, we directly follow the depreciation rate and the schedule given in Singh et al. (2018). According to them, a 5.28\% rate is applicable for the first 12 years, and the remaining $90 \%$ is evenly distributed from the 13th year to the 60th year.

\footnotetext{
5 The $90 \%$ depreciation rate and $10 \%$ salvage value are estimated following both Bangladesh Energy Regulatory Association (2016) and Singh et al. (2018). In contrast, the 10-year and 50-year schedule are following the depreciation schedule given in Bangladesh Energy Regulatory Association (2016).
}

\section{Decommissioning cost}

We estimate $10 \%$ of the overnight cost as the decommissioning cost for Bangladesh, following the World Nuclear Association (2020) due to the unavailability of real-life data. According to our estimation, the decommissioning cost is $\$ 527$ million for Bangladesh. On the other hand, in the case of India, we follow Singh et al. (2018) to estimate the decommissioning cost at $\$ 340$ million. We estimate a separate decommissioning cost because it primarily depends on country context, reactor type, and plant size (Singh et al. 2018). Therefore, in the context of India, this study follows Singh et al. (2018), which provides an estimation of approximately $10 \%$ of the overnight cost.

\section{Inflation rate and escalation factors}

We estimate $6 \%$ for Bangladesh and India based on the last 5 years' inflation rate for these two countries. Most of the studies followed MIT $(2003,2009)$ and Du and Parsons (2009), using a 3\% inflation rate; however, $3 \%$ inflation is not appropriate in real-life data in India and Bangladesh. On the other hand, following Singh et al. (2018), MIT (2003, 2009), Du and Parsons (2009), we assume $1 \%$ real escalation in $\mathrm{O} \& \mathrm{M}$ and $0.5 \%$ real escalation in fuel cost.

\section{Cost of debt, return on equity, and weighted average of capital}

A debt-equity ratio of 90/10 was agreed between Bangladesh, Rooppur NPP, and Russian company Rustom (World Nuclear Association 2020). In contrast, following the Bangladesh Energy Regulatory Association (2016) estimation, we assume a return on equity of $20 \%$ and the cost of debt as $12.90 \%$ in the context of Bangladesh. Thus, combining these rates gives us a weighted average cost of capital (WACC) of 9.26\%, which is used to estimate the project's after-tax cash flows to yield the net present value. On the other hand, in the case of India, we assume an $85 / 15$ debt-equity ratio according to their agreement with Rustom. Moreover, we calculate return on equity is $23.48 \%$, and the cost of debt is $8 \%$, following Singh et al. (2018). Thus, it implies a WACC of $7.94 \%$ in the case of India's LCOE estimation.

\section{Income tax}

MIT (2003, 2009) and Du and Parsons (2009) assume the income tax rate as $37 \%$ for the LCOE estimation. Furthermore, we follow Singh et al. 2018) in India and estimate a 34\% income tax rate for NPP. We determine a $37.5 \%$ tax rate for Bangladesh Energy Regulatory Association (2016) guideline. 
Table 4 The base case input parameters for Bangladesh

\begin{tabular}{|c|c|c|c|}
\hline & Input & Units & Nuclear \\
\hline [1] & Capacity & MW & 2,400 \\
\hline [2] & Capacity factor & & $85 \%$ \\
\hline [3] & Heat rate & $\mathrm{Btu} / \mathrm{kWh}$ & 10,400 \\
\hline [4] & Overnight cost & $\$ / \mathrm{kW}$ & 5,271 \\
\hline [5] & Interest during construction (IDC) & $\$ / \mathrm{kW} /$ year & 2108.40 \\
\hline [6] & Incremental capital cost & $\$ / \mathrm{kW} /$ year & 51.71 \\
\hline [7] & Fixed O\&M costs & $\$ / \mathrm{kW} /$ year & 91.45 \\
\hline [8] & Variable $\mathrm{O} \& \mathrm{M}$ costs & mills/kWh & 0.69 \\
\hline [9] & Fuel costs & \$/MMBtu & 0.68 \\
\hline$[10]$ & Waste fee & $\$ / \mathrm{kWh}$ & 0.001 \\
\hline [11] & Decommissioning cost & $\$$ million & 527 \\
\hline [12] & Inflation rate & & $6.0 \%$ \\
\hline [13] & O\&M real escalation & & $1.0 \%$ \\
\hline [14] & Fuel real escalation & & $0.5 \%$ \\
\hline [15] & Tax Rate & & $37.5 \%$ \\
\hline [16] & Debt fraction & & $90 \%$ \\
\hline [17] & Debt rate & & $12.90 \%$ \\
\hline [18] & Equity rate & & $20 \%$ \\
\hline [19] & WACC (weighted avg cost of capital) & & $9.26 \%$ \\
\hline \multirow[t]{9}{*}{ [20] } & Construction schedule & & \\
\hline & Year 7 & & $0 \%$ \\
\hline & Year 6 & & $6 \%$ \\
\hline & Year 5 & & $10 \%$ \\
\hline & Year 4 & & $20 \%$ \\
\hline & Year 3 & & $20 \%$ \\
\hline & Year 2 & & $25 \%$ \\
\hline & Year 1 & & $10 \%$ \\
\hline & Year 0 & & $9 \%$ \\
\hline \multirow[t]{2}{*}{ [21] } & Depreciation schedule & & \\
\hline & Year 1 & & $3.20 \%$ \\
\hline
\end{tabular}

Source: Authors' calculation

\section{External cost}

Since Bangladesh has just started its first NPP, it incurs some external costs during its pre-construction and construction phase. Therefore, we estimate an external cost of USD 187.5 million for Bangladesh while evaluating the LCOE based on different setup cost calculations.

The following two tables represent a year-wise construction schedule and the estimated cost parameters for the two countries (Tables 4 and 5). The dataset is available in the repository of Harvard Dataverse at https://doi.org/10. 7910/DVN/UGJCUW. This will help all the researchers and reviewers to replicate all the results used in the paper.
Table 5 The base case input parameters for India

\begin{tabular}{|c|c|c|c|}
\hline & Input & Units & Nuclear \\
\hline [1] & Capacity & MW & 2,000 \\
\hline [2] & Capacity factor & & $85 \%$ \\
\hline [3] & Heat rate & $\mathrm{Btu} / \mathrm{kWh}$ & 10,400 \\
\hline [4] & Overnight cost & $\$ / \mathrm{kW}$ & 3125 \\
\hline [5] & Interest during construction (IDC) & $\$ / \mathrm{kW} /$ year & 1250 \\
\hline [6] & Incremental capital cost & $\$ / \mathrm{kW} /$ year & 31.25 \\
\hline [7] & Fixed O\&M costs & $\$ / \mathrm{kW} /$ year & 91.45 \\
\hline [8] & Variable $\mathrm{O} \& \mathrm{M}$ costs & mills/kWh & 0.69 \\
\hline [9] & Fuel costs & \$/MMBtu & 0.68 \\
\hline$[10]$ & Waste fee & $\$ / \mathrm{kWh}$ & 0.001 \\
\hline [11] & Decommissioning cost & $\$$ million & 340 \\
\hline [12] & Inflation rate & & $6.0 \%$ \\
\hline [13] & O\&M real escalation & & $1.0 \%$ \\
\hline$[14]$ & Fuel real escalation & & $0.5 \%$ \\
\hline$[15]$ & Tax rate & & $34 \%$ \\
\hline [16] & Debt fraction & & $85 \%$ \\
\hline [17] & Debt rate & & $8 \%$ \\
\hline$[18]$ & Equity rate & & $23 \%$ \\
\hline [19] & WACC (weighted avg cost of capital) & & $7.94 \%$ \\
\hline \multirow[t]{9}{*}{ [20] } & Construction schedule & & \\
\hline & Year 7 & & $0 \%$ \\
\hline & Year 6 & & $6 \%$ \\
\hline & Year 5 & & $10 \%$ \\
\hline & Year 4 & & $20 \%$ \\
\hline & Year 3 & & $20 \%$ \\
\hline & Year 2 & & $25 \%$ \\
\hline & Year 1 & & $10 \%$ \\
\hline & Year 0 & & $9 \%$ \\
\hline \multirow[t]{2}{*}{ [21] } & Depreciation schedule & & \\
\hline & Year 1 & & $5.28 \%$ \\
\hline
\end{tabular}

Source: Authors' calculation

Table 6 Comparison of LCOE for Bangladesh Rooppur NPP and Kudankulam NPP

\begin{tabular}{lll}
\hline Country & & The capacity of power plant \\
\hline Bangladesh & LCOE US cent $/ \mathrm{kWh}$ & $2400 \mathrm{MW}$ \\
& & $9.36 \mathrm{cents} / \mathrm{kWh}$ \\
India & LCOE US cent $/ \mathrm{kWh}$ & $2000 \mathrm{MW}$ \\
& & $5.34 \mathrm{cents} / \mathrm{kWh}$ \\
\hline
\end{tabular}

\section{Interpretation of the cost estimation result}

The tables and graphs discussed in this section are calculated using Du and Parsons (2009) spreadsheet model of LCOE estimation. We first discuss the result of the base case analysis, following the discussion of the sensitivity analysis result. Our baseline cost model results suggest 
that the LCOE of Bangladesh is 9.35 US cents $/ \mathrm{kWh}$ considering a 2400 MW capacity of Rooppur NPP. Our result is similar to the JICA's estimation of 9 US cents $/ \mathrm{kWh}$ using the 2010 US dollar (Table 6). On the other hand, this cost is also identical to the findings of MIT (2003, 2009), Du and Parsons (2009). Therefore, it indicates that the LCOE in Bangladesh is at par with other countries in the world.

Furthermore, we also examine the Kudankulam NPP of India, and the results indicate that for $2000 \mathrm{MW}$ capacity (which is the total capacity of Kudankulam 3 and 4), the LCOE is 5.36 cents $/ \mathrm{kWh}$.

Therefore, our results clearly show that India's LCOE is lower than Bangladesh for several reasons. First, according to the agreement, the construction cost is more than double in Bangladesh compared to India. Further, Bangladesh incurs an additional external cost of USD 187.5 million. Bangladesh will establish its first NPP, so it faces a setup cost for different facilities, i.e., telecommunications, transportation, water line establishment, and gridline establishment. In contrast, Kudankulam 3 and 4 will be India's 25th and 26th nuclear power reactors. Figure 1 represents the percentage of key cost components in the LCOE estimation for Bangladesh and India. In the case of Bangladesh, the external cost has a 5\% share in total LCOE estimation where the share of the capital cost is $76 \%$, share of IDC and decommissioning cost is $3 \%$, the share of non-fuel O\&M cost is 7\%, and combined share of fuel cost and the waste fee is $9 \%$, respectively.

Meanwhile, in India, there is no external cost in percentage share of total LCOE estimation, where the capital cost share is $64 \%$, the share of IDC and decommissioning cost together is $4 \%$, and the share of non-fuel O\&M cost is $16 \%$. The combined share of fuel cost and the waste fee is $16 \%$ accordingly. Therefore, it is evident that the share of external cost has a significant role in LCOE estimation in the case of Bangladesh.

On the other hand, in the case of India, LCOE is pretty competitive and similar to the findings of Bharadwaj et al. (2006) and Bharadwaj et al. (2008). In contrast, Singh et al. (2018) estimated an exceptionally high LCOE for NPP in their recent study. This is because, in the case of India, our study considers 2000 MW (two units together) capacity with a given overnight cost according to the agreement with Rustom, Russia, while other studies assume a theoretical $1000 \mathrm{MW}$ capacity for one unit, for a range of overnight cost of $\$ 2000-\$ 3000 \mathrm{KW}$. We calculate the actual per $\mathrm{kW}$ overnight cost according to the agreement between Russian Rustom and India. Therefore, we find a more competitive cost of NPP for India compared to other studies. Our overall result detects economics of scale in the production of nuclear power electricity in both Bangladesh and India.

As discussed earlier, the LCOE of nuclear power is competitive with other energy sources, given the electricity market structure of Bangladesh. However, the literature suggests that carbon tax makes the LCOE of nuclear electricity competitive even in deregulated electricity markets (Du and Parsons 2009; Kennedy 2007; Yu et al. 2020). Thus, if the Bangladesh government introduces a carbon tax on fossil fuel electricity production, the LCOE of nuclear energy will be more competitive under Bangladesh's centralized and regulated electricity market.

In this context, it can be noted that the electricity market of Bangladesh, regulated centrally by the Ministry of Power, Energy, and Natural Resources (Asian Development Bank, 2020). The consumer side of the electricity market is represented by agricultural, residential, and industrial buyers. As mentioned earlier, the electricity demand has substantially increased in Bangladesh due to economic size, which indicates an expanding market. On the other hand, the supply side is fully controlled by the government. Bangladesh Power Development Board (BPDB) produced a significant fraction of electricity and served as the single buyer in the electricity market (Mostafa et al. 2017). The Bangladesh government also works with independent power producer (IPP) to produce electricity through a public-private partnership. However, BPDB buys all the electricity from all the producers and has a monopoly over transmission and distribution. BPDB is the only retail supplier that supplies
Fig. 1 Percentage distribution of the key cost components in LCOE estimation in Bangladesh and India. Source: Own calculation from the model data

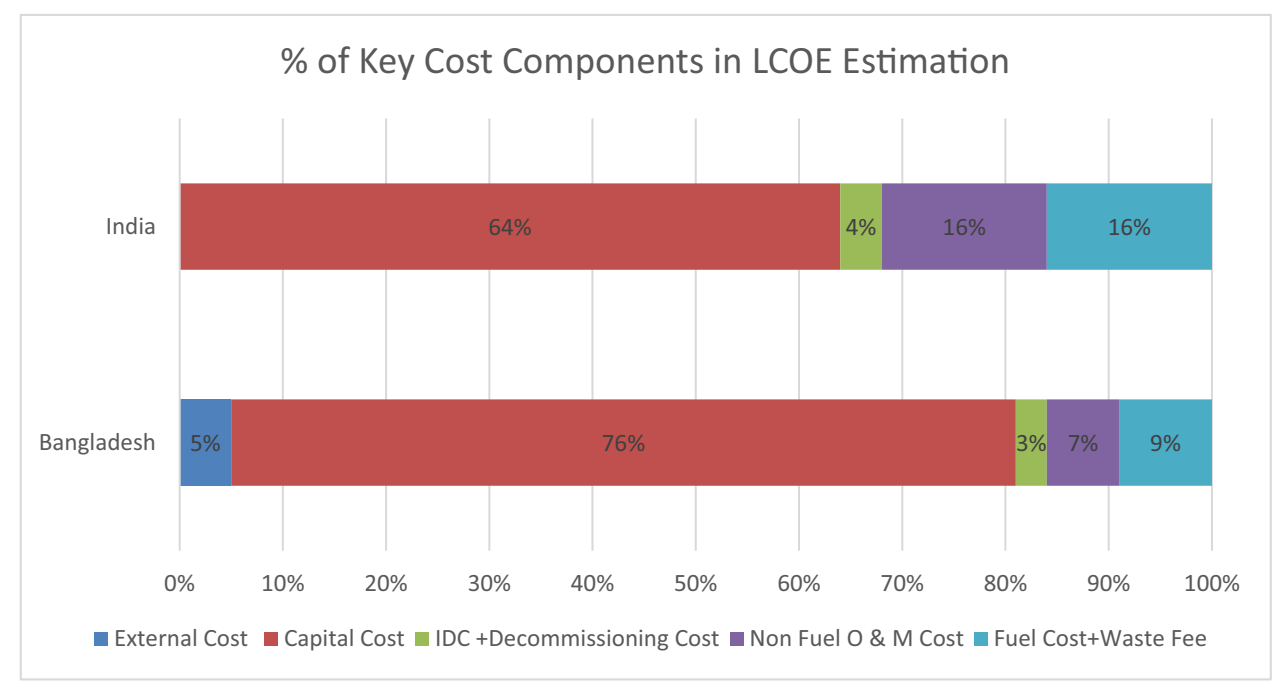


Table 7 The result of the sensitivity analysis for Bangladesh

\begin{tabular}{lcc}
\hline Variable & & LCOE \\
\hline Overnight cost & & \\
Baseline & 5271.00 & 9.35 \\
Lower & 3000.00 & 8.57 \\
Upper & 6000.00 & 9.60 \\
Interest during construction & & \\
Baseline & 2108.40 & 9.35 \\
Lower & 1687.00 & 7.35 \\
Upper & 2531.00 & 10.01 \\
Fixed O\&M cost & & \\
Baseline & 91.45 & 9.35 \\
Lower & 73.16 & 9.21 \\
Upper & 110.35 & 9.49 \\
Inflation & & \\
Baseline & $6.00 \%$ & 9.35 \\
Lower & $3.00 \%$ & 15.78 \\
Upper & $10.00 \%$ & 4.38 \\
Tax rate & & \\
Baseline & $37.50 \%$ & 13.87 \\
Lower & $30.00 \%$ & 8.56 \\
Upper & $45.00 \%$ & 10.35 \\
WACC & & \\
Baseline & $9.26 \%$ & 9.35 \\
Lower & $8.0 \%$ & 7.40 \\
Upper & $12.0 \%$ & 14.81 \\
\hline
\end{tabular}

Source: Authors' calculation

electricity to consumers. Thus, currently, nuclear will be a beneficial option for the government compared to other electricity sources in production costs and energy security issues.

\section{Sensitivity test result}

Besides the base case estimation, we conducted a sensitivity analysis to examine the effect of uncertainty over different cost parameters in both countries. To examine the uncertainty of cost input parameters, we select overnight cost, fixed operation and maintenance cost, interest during construction, tax rate, inflation, and the weighted average cost of capital to deviate from its base value. For each variable, the upper limit and the lower limit are selected from various literatures to get a broader picture of a wide range of uncertainties around the base values. It is important to note that the upper and lower limits may depend on the country's context. Thus, the following two tables represent each cost input parameter's upper and lower values with their base values and respective LCOE (Tables 7 and 8).

Furthermore, Figs. 2 and 3 show the result of the sensitivity analysis of LCOE for both Bangladesh and India.

Our results show that changes in inflation and WACC (which work as a discount rate in the analysis) have the highest
Table 8 The result of the sensitivity analysis for India

\begin{tabular}{lcc}
\hline Variable & & LCOE \\
\hline Overnight cost & & \\
$\quad$ Baseline & 3125.00 & 5.36 \\
Lower & 2000.00 & 5.05 \\
Upper & 4000.00 & 5.59 \\
Interest during construction & & \\
$\quad$ Baseline & 1250.00 & 5.36 \\
Lower & 787.50 & 4.40 \\
Upper & 1417.00 & 5.70 \\
Fixed O and M cost & & \\
Baseline & 91.45 & 5.36 \\
Lower & 73.16 & 5.18 \\
Upper & 110.35 & 5.53 \\
Inflation & & \\
Baseline & $6.00 \%$ & 5.36 \\
Lower & $3.00 \%$ & 8.78 \\
Upper & $10.00 \%$ & 3.05 \\
Tax rate & & \\
Baseline & $34.00 \%$ & 5.36 \\
Lower & $30.00 \%$ & 5.17 \\
Upper & $45.00 \%$ & 6.01 \\
WACC & & \\
Baseline & $7.94 \%$ & 5.36 \\
Lower & $5.00 \%$ & 3.43 \\
Upper & $10.00 \%$ & 7.46 \\
\hline Source: & &
\end{tabular}

Source: Authors' calculation

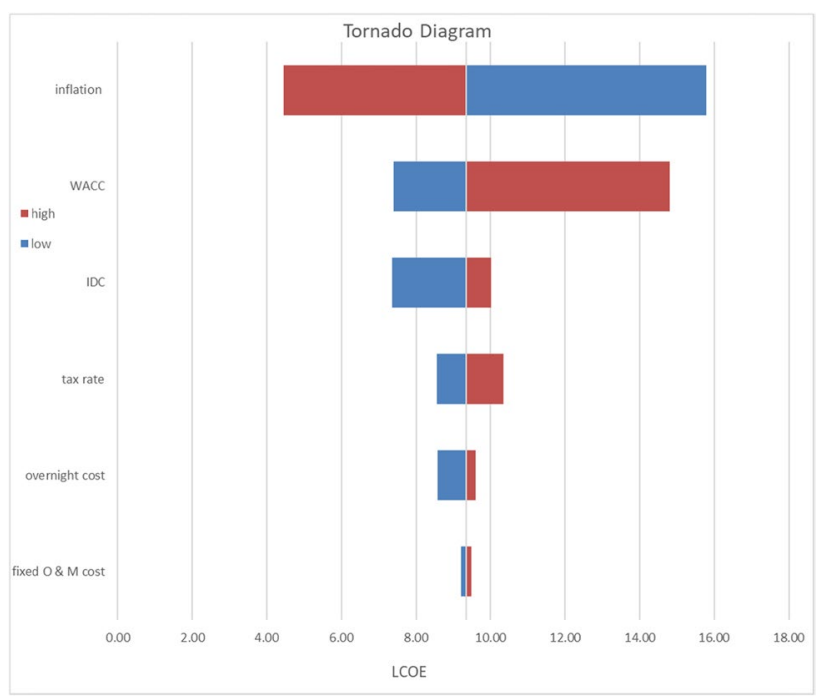

Fig. 2 Tornado diagram for LCOE of Bangladesh. Source: Authors' calculation

impact on LCOE. The least significant impact is induced by fixed operation and maintenance costs. The pattern of the result is the same for both India and Bangladesh. Thus, our sensitivity analysis ensures that uncertainty around different cost parameters for the given LCOE estimation model causes the same effect on the LCOE of NPP. The absolute 
Fig. 3 Tornado diagram for LCOE of India. Source:

Authors' calculation

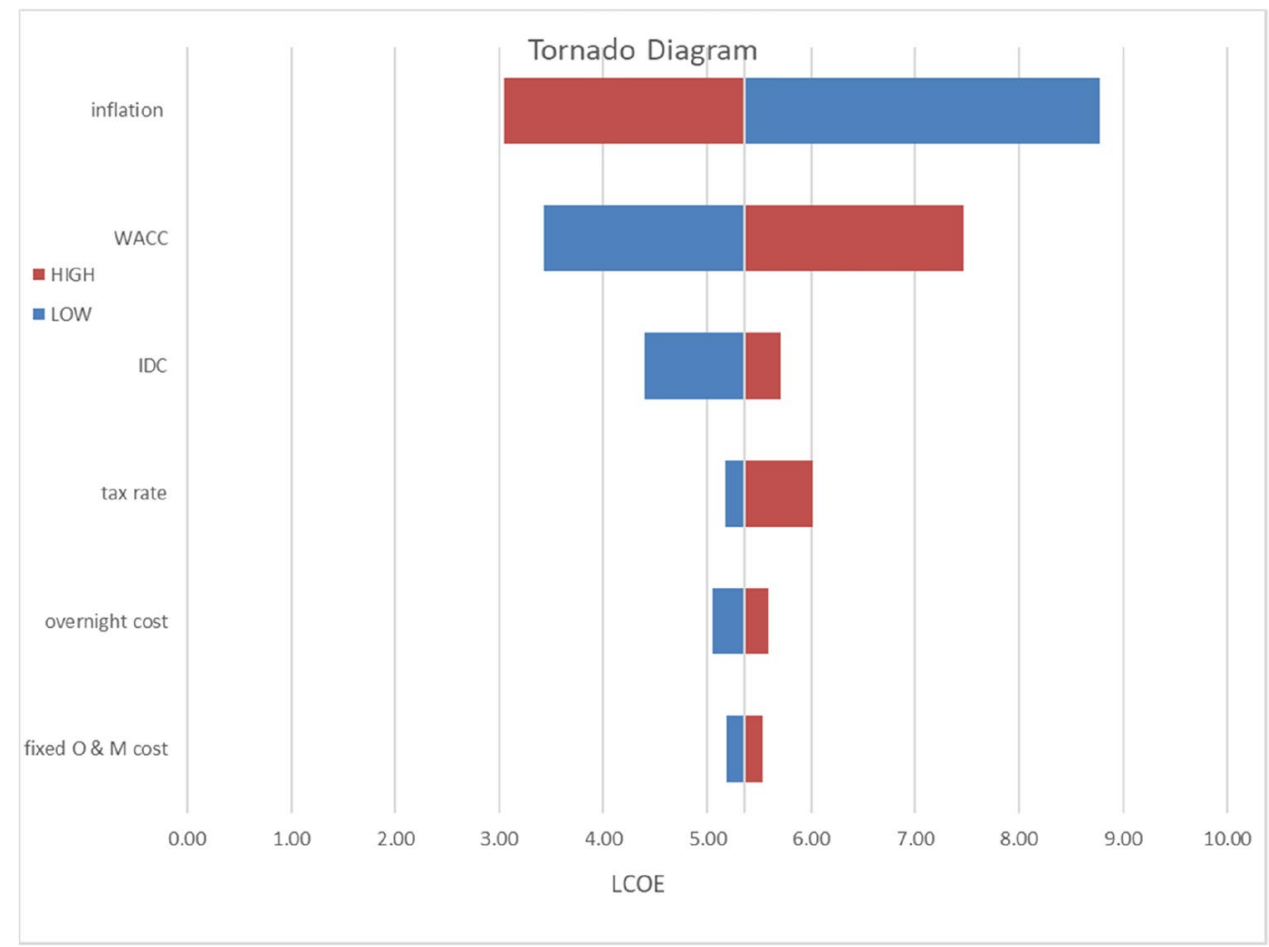

value change of LCOE may differ from one country to another, but the impact of percentage change is similar. For example, in India and Bangladesh, the highest effect is induced by the inflation rate followed by WACC, interest during construction, overnight cost, and fixed operation and maintenance cost. In addition, it is crucial to recognize that overnight cost, WACC, tax rate, fixed operation, and maintenance cost have a positive relationship with LCOE. On the other hand, inflation has an inverse relationship with LCOE. Thus, the country with a higher inflation rate will have a lower LCOE and vice versa.

Figures 4 and 5 clearly show how LCOE changes for both Bangladesh and India for every low and high value of the cost parameters. In the context of Bangladesh, the following result suggests that when WACC is $8 \%$ and $12 \%$, the LCOE is 7.40 cents/ $\mathrm{kWh}$ and 14.81 cents/kWh, respectively. It induces a 7.41 cents/ $\mathrm{kWh}$ change in LCOE, whereas for a $3 \%$ inflation rate, the LCOE is 15.78 cents/ $/ \mathrm{kWh}$, and for a $10 \%$ inflation rate, it is 4.45 cents/ $\mathrm{kWh}$. Therefore, the impact of a change in the inflation rate is larger than any other factor. On the other hand, in Kudankulam, for 5\% and $10 \%$ WACC, the LCOE is 3.43 cents $/ \mathrm{kWh}$ and 7.46 cents/ $\mathrm{kWh}$, respectively. Moreover, for a $3 \%$ inflation rate, the LCOE is 8.78 cents/ $/ \mathrm{kWh}$, and for a $10 \%$ inflation, it is 3.05 cents $/ \mathrm{kWh}$.

Finally, our sensitivity result shows that, due to a change in fixed operation and maintenance cost for Bangladesh and India, the absolute difference between the upper and the lower values of LCOE is 0.28 and 0.35 , respectively. Therefore, the operation and maintenance costs have the lowest impact on the LCOE of nuclear power estimation. A detailed simulation result for the two countries is also provided.

\section{Relevance for the estimated cost}

The findings of our study are highly relevant in the context of the electricity sector of Bangladesh. No study has so far calculated the LCOE of electricity for any fuel in Bangladesh. Table 9 represents the per $\mathrm{kWh}$ generation cost of electricity from different sources owned by the public power plant in 2018-2019 (Bangladesh Power Development Board 2020) and the electricity purchase cost for Bangladesh Power Development Board for the year 2018-2019.

It shows that wind-generated electricity has the highest generation cost, where the lowest costs are for hydroelectricity power generation. The costs are BDT $81.88 / \mathrm{kWh}$ and BDT $1.00 / \mathrm{kWh}$, respectively. The table, additionally, shows the cost of electricity generation using gas, coal, heavy fuel oil (HFO), high-speed diesel (HSD), and solar. The purchase cost per kWh may vary depending on the ownership of the plant. According to the table, the lowest purchase cost is for IPP- and SIPPowned power plants for gas-generated electricity. The highest purchase cost is for HSD-generated electricity purchased from rental and quick rental. These costs are BDT $2.47 / \mathrm{kWh}$ and BDT 27.46/kWh, respectively. Bangladesh Power Development Board buys electricity from these producers at their prices and supplies them to different consumers using various tariff rates.

In addition, the Bangladesh government utilizes different electricity tariff rates for different consumer groups (Table 10).

The rates indicate that the Bangladesh government follows a discriminatory price policy based on the need of consumers. The 
Fig. 4 Levelized cost of nuclear power plant in Bangladesh for different scenarios of highcost and low-cost parameters Source: Own calculation from the model data

Fig. 5 Levelized cost of nuclear power plant in India for different scenarios of high-cost and low-cost parameters Source: Own calculation from the model data
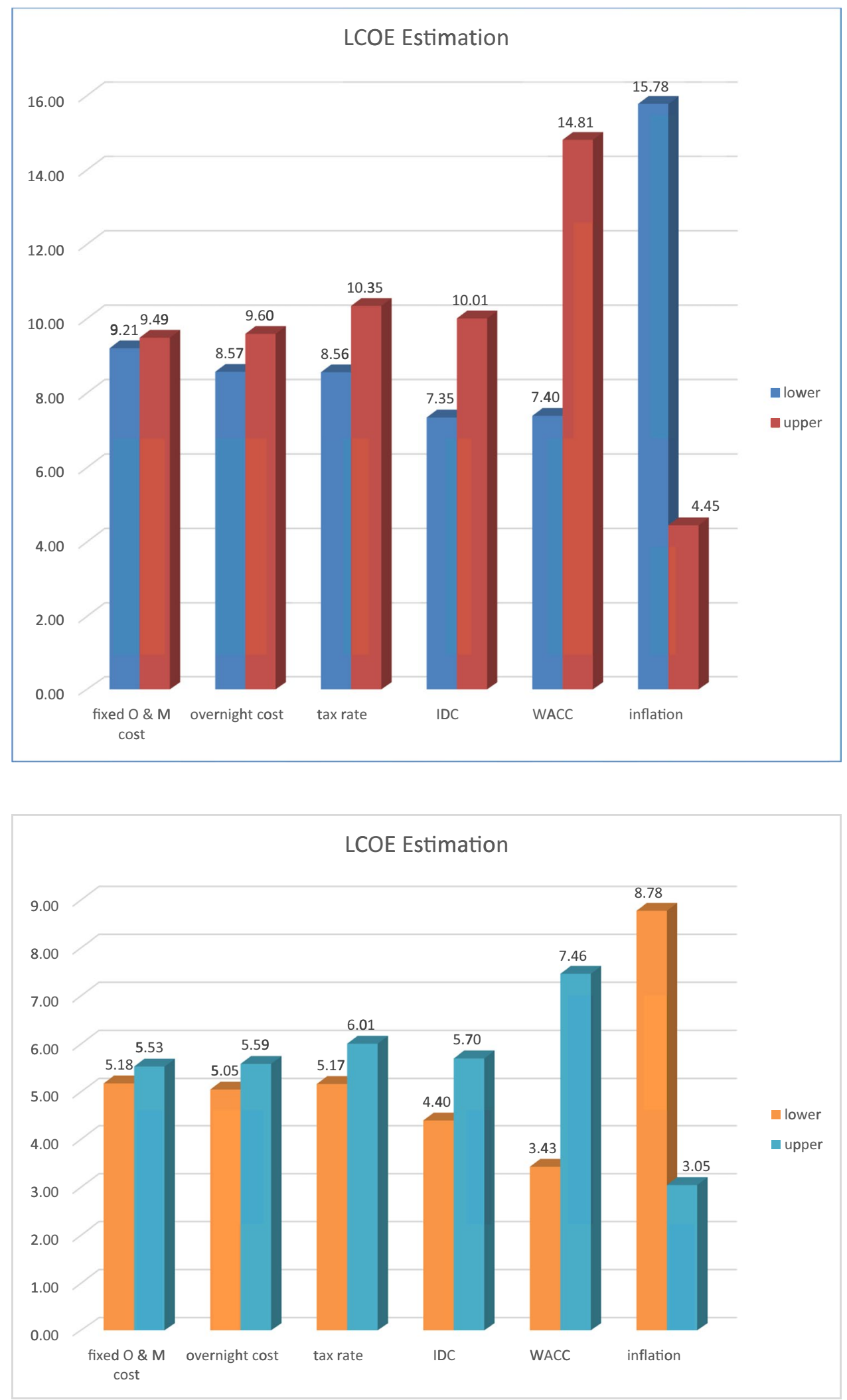

lowest tariff rate applies to agricultural customers (BDT 4.16/ $\mathrm{kWh}$ ), whereas office and commercial consumers pay the highest tariff rate (BDT $10.30 / \mathrm{kWh}$ ). There is a marginal pricing system for a different set of consumption units; thus, this study calculates a flat average tariff rate of BDT $7.90 / \mathrm{kWh}$ for this group of consumers. We can understand that the Bangladesh government 
Table 9 Generation cost and purchase cost of electricity by fuel source $(\mathrm{BDT} / \mathrm{kWh})$

\begin{tabular}{lll}
\hline Source of fuel & $\begin{array}{l}\text { Generation cost Tk/kWh } \\
(2018-2019) *\end{array}$ & $\begin{array}{l}\text { Purchase cost Tk/ } \\
\mathrm{kWh}(2018-2019)\end{array}$ \\
\hline Domestic gas & 2.57 & $2.47^{* * *}$ \\
& & $2.62^{* * *}$ \\
& & $4.22^{* * * *}$ \\
HSD & 26.00 & $20.59^{* *}$ \\
& & $18.02^{* * *}$ \\
& & $27.46 * * * *$ \\
Imported coal & 8.10 & $\mathrm{~N} / \mathrm{A}$ \\
Domestic coal & 6.00 & $\mathrm{~N} / \mathrm{A}$ \\
Wind & 81.88 & $\mathrm{~N} / \mathrm{A}$ \\
Solar & 12.00 & $16.4^{* *}$ \\
Imported power & 6.48 & $\mathrm{~N} / \mathrm{A}$ \\
Hydro & 1.00 & $\mathrm{~N} / \mathrm{A}$ \\
HFO & 17.00 & $10.38^{* * *}$ \\
& & $13.26^{* * *}$ \\
& & $11.20^{* * * *}$ \\
\hline
\end{tabular}

Source: Compilation by authors from Bangladesh Power Development Board (BPDB 2020) and eighth 5-year plan of Bangladesh, 2021.

Notes.

*All the generation cost is based on rates from public plant owned by BPDB.

**From independent power producer (IPP) and small independent power producer (SIPP).

***From subpublic plant.

****From rental and quick rental.

heavily subsidizes the electricity sector operating at two stages. First, the government subsidizes the production cost of electricity and provides further subsidies while supplying the electricity to different consumer groups. Therefore, the consumers are paying a tariff lower than the actual production cost of electricity.

Consequently, the policy implication of LCOE analysis is crucial for Bangladesh. Our findings suggest that the LCOE of Bangladesh is BDT 7.94/kWh. Hence, if the government can sell the electricity above this price, it will earn a profit. The government may yield a lower return to capital or incur a loss if the government sells electricity below this threshold level. Therefore, nuclear

Table 10 Tariff rates by different consumer categories (BDT/kWh) $* * *$

\begin{tabular}{lc}
\hline Tariff & Flat rate \\
\hline Residential & $7.90^{*}$ \\
Agricultural & 4.16 \\
Small industries & $8.53^{* *}$ \\
Non-residential & 7.70 \\
Commercial and office & $10.30^{* *}$ \\
\hline
\end{tabular}

Source: *This flat rate is the average rate calculated by the authors.

**Flat tariff rate is considered.

***All are based on low tension 230/400 V. power can be considered cost-competitive if hydroelectric and gas production costs are lower than nuclear (Table 9). However, it is essential to note that per-unit production cost and LCOE follow different estimation techniques. LCOE estimates discounted revenue and cost considering the plant lifetime. Hence, the actual per-unit production cost will be much lower than the LCOE estimation. Even though we consider the LCOE of nuclear, it is still lower than imported coal, solar, HFO, HSD, and wind production cost. Thus, it is evident that nuclear will be more beneficial compared to all other sources. It is also important to note that gas is a depletable resource in Bangladesh and hydroelectricity is not a feasible option due to the characteristics of rivers of the country.

Moreover, coal emits high levels of $\mathrm{CO} 2$, whereas nuclear power has zero carbon emissions. Power generation through wind is an expensive option among renewables, which exhibits BDT $81.88 / \mathrm{kWh}$ production cost, whereas solar is a reasonable option. However, nuclear has baseload power generation that ensures uninterrupted electricity supply, whereas solar production does not ensure an uninterrupted electricity supply since it is highly dependent on weather conditions.

Finally, the subsidy amount will also be smaller than other electricity sources if we consider the tariff rate. Therefore, in Bangladesh, nuclear power is a viable energy option to have in the energy basket. Our results suggest that introducing nuclear power will increase our electricity supply at a competitive cost. Even when we compare our LCOE with India, we notice that Bangladesh may have higher LCOE, but this is because Rooppur NPP is the first nuclear power plant, and we are facing an external cost of US $\$ 187.5$ million because of that. Thus, in the future, it may become more cost-efficient compared to India.

Furthermore, it is an excellent option to produce electricity in a cost-competitive manner within the country's context. This study finds nuclear power to be an effective viable option for energy diversification, and it should be included in the energy basket of Bangladesh in the long run. Nuclear power will provide sufficient energy security and diversification, along with zero carbon emissions in Bangladesh.

\section{Conclusion and policy implications}

In Bangladesh, the increasing electricity demand is triggered by the growing size of the economy and its transformation to modernization. According to the Bangladesh government's calculation, access to electricity is $90 \%$, while, according to World Development Indicator, in 2018, 85\% of the population had access to electricity. Therefore, $10-15 \%$ of the population is deprived of electricity facilities. Bangladesh's government needs to establish an uninterrupted diversified power supply system to ensure $100 \%$ access to electricity and meet the growing demand for industrial activities. As mentioned earlier, it is also vital to reduce the dependence on natural gas and oil-based electricity due to the depletion of resources and the negative environmental 
impact. Furthermore, along with coal and solar power, nuclear power plays a vital role in Bangladesh government's power supply master plan. The Bangladesh government believes the Rooppur mega project will maintain a secure power supply and reduce $\mathrm{CO}_{2}$ emissions at a lower operating cost.

However, there is an increasing concern about the enormous amount construction cost of nuclear power. In Bangladesh, the cost of producing electricity is always higher than the price of electricity. According to Bangladesh government, in the last 10 years, the amount of subsidy given to the power sector was equal to BDT 522.6 billion due to higher production costs and lower selling price of electricity. Therefore, it is also critical to ensure an affordable production cost of electricity to minimize the subsidy burden. Hence, it is crucial to understand the economics of nuclear power in Bangladesh, examining the levelized cost of electricity from nuclear power plants using a standard levelized cost-based financial model. In this paper, we have made the noble attempt to conduct a thorough economic cost analysis of setting up the first nuclear power plant at Rooppur in Bangladesh by using the unique discounted present value method developed by Du and Parsons (2009), MIT (2003; 2009; 2018), and Singh et al. (2018). This paper did it uniquely in Bangladesh, soon becoming another nuclear power in South Asia after India and Pakistan.

We compared the levelized cost of Bangladesh with India to examine the broader picture of nuclear power-generated electricity. This study develops this model, including all the vital cost parameters, i.e., overnight cost, decommissioning cost, operating cost, and financial components such as interest during construction, incremental capital cost, cost debt, and the weighted average cost of capital, depreciation cost, tax rate, and others. Our assumption regarding various input parameters is based on a detailed literature review and country-specific contexts. The base case estimation suggests that the LCOE of Rooppur NPP is 9.36 US cents $/ \mathrm{kWh}$ or BDT 7.94 per $\mathrm{kWh}$ (with an exchange rate of $\$ 1=$ BDT 84.877, which is $0.84877 \times 9.36=7.94)$. The LCOE of Kudankulam India is $5.36 \mathrm{US}$ cents/kWh or 3.93 Indian Rupee/kWh (with an exchange rate of $\$ 1=73.4$ Indian Rupee which is $0.734 \times 5.36=3.93$ ).

Along with base case estimation, this study conducts a sensitivity analysis on key input parameters. We use a range of values around the base values of key input parameters to see the impact on LCOE estimations. Our results suggest that the inflation rate, the weighted average cost of capital, and IDC significantly impact LCOE.

Following the findings, this paper strongly suggests that nuclear power is a worthwhile option for electricity production in Bangladesh, considering energy security, diversifications of energy basket, zero carbon emission, and cost-competitiveness. In the future, if solar and other renewables become more costcompetitive, these may compete with nuclear power. However, nuclear power will still be appealing even comparing renewables because of its baseload power generation. The drawback of nuclear in Bangladesh is its high risk of accidents, which will induce a considerable cost with a significant level of health hazard. Furthermore, without foreign investment, it will be hard for the Bangladesh government to bear the construction cost of nuclear power and technological support. Nevertheless, the latest technology ensures the minimum risk of nuclear accidents. Thus, if Bangladesh government can ensure foreign investment to build nuclear power plants, it may become an attractive option to produce electricity.

Moreover, the Bangladesh government plans to diversify its power generation to meet low-cost fuel and low carbon emission criteria. Therefore, according to the eighth 5-year plan, the Bangladesh government has revised its nuclearproduced electricity target. Currently, the government plans to produce $14 \%$ of power from nuclear sources in 2031 and $12 \%$ in 2041 (Moazzem \& Shibly 2021). Furthermore, the Bangladesh government has taken various initiatives in the 8th 5 -year plan to achieve green growth under environmental and climate change strategies. The government plans to introduce an emission accounting strategy that will make the polluters bound to pay (GED 2020). The government also has a plan for decarbonatization or a policy of a low carbon economy. Thus, the government has a target for low fossil-fuel use along with low-greenhouse gas emissions. Therefore, if the government can implement these plans and introduce a carbon tax in Bangladesh, nuclear will be a better option than other fossil fuel alternatives for baseload uninterrupted power supply. Meanwhile, as a part of reducing $\mathrm{CO} 2$ emission, the government also has a plan to increase the share of renewable use, which may work as a constraint to nuclear expansion. However, as discussed earlier in developing countries, renewable energy may not suppress the demand for nuclear electricity due to baseload uninterrupted power supply.

The electricity market of Bangladesh is highly regulated and centralized by the Ministry of Power and Bangladesh Power Development Board (BPDB). Hence, as only transmitter and distributor and supplier of electricity, nuclear electricity may be a good option in the short run. In the long run, deregulation and privatization of the power sector may take place. At that stage, carbon tax and other environmental regulations may make nuclear a profitable option compared to other electricity sources. Furthermore, nuclear technology requires highly skilled workers. Currently, Bangladesh entirely depends on Russian technological support. Hence, in the short run, this intuitional setup may work well. However, in the long run, if government wants to expand its nuclear production, it should arrange full technological support and necessary training facilities for skilled workers at the domestic level.

This study only estimates the LCOE of nuclear power in the context of Rooppur, Bangladesh, and Kudankulam, India, then compares them. Further research may explore the LCOE of other vital sources of electricity production in Bangladesh, such as coal, solar, HFO, HSD, and others. That will provide a complete picture of the cost of producing electricity in terms of LCOE in Bangladesh and help policymakers set their future energy policy and electricity production targets. 


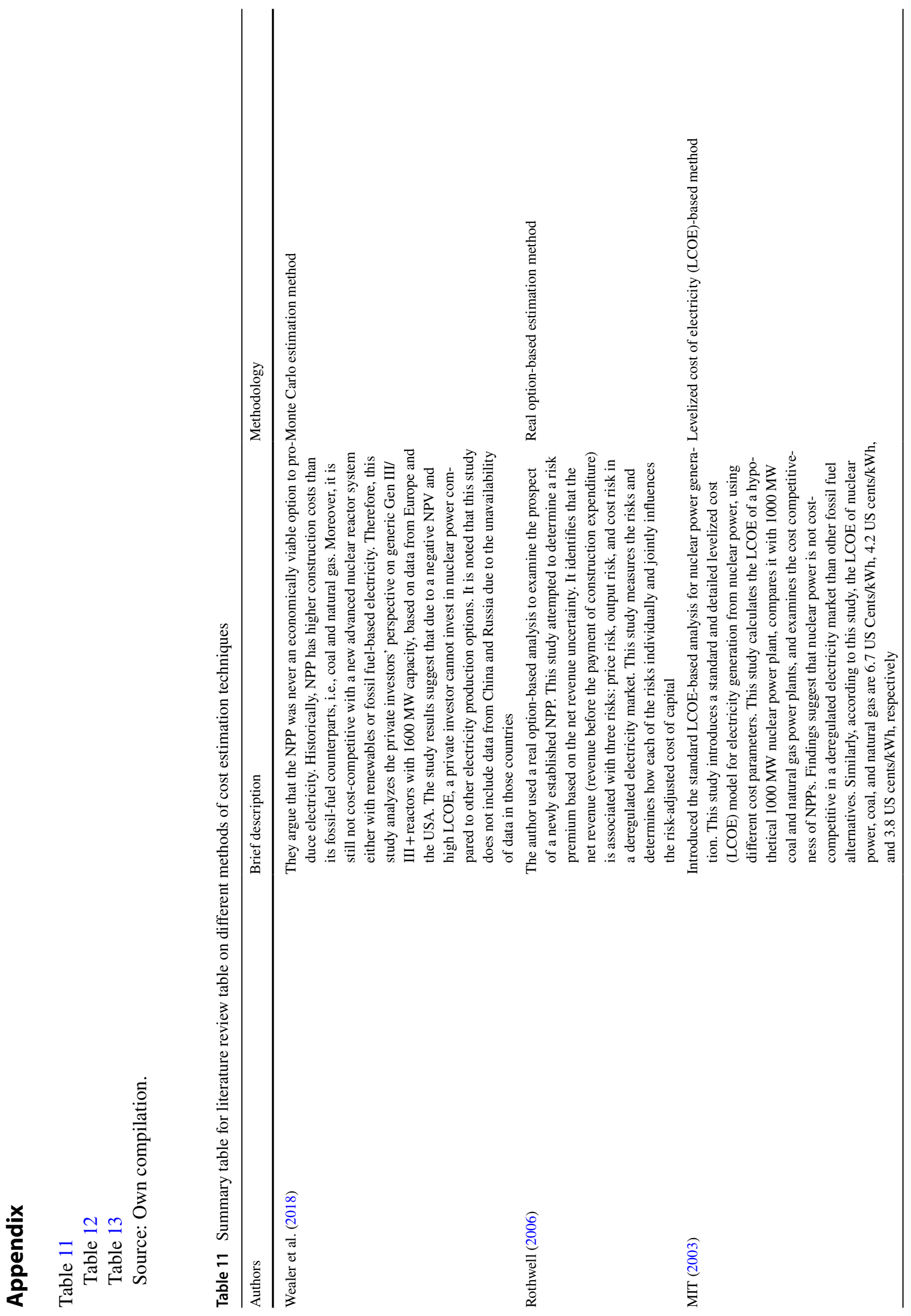




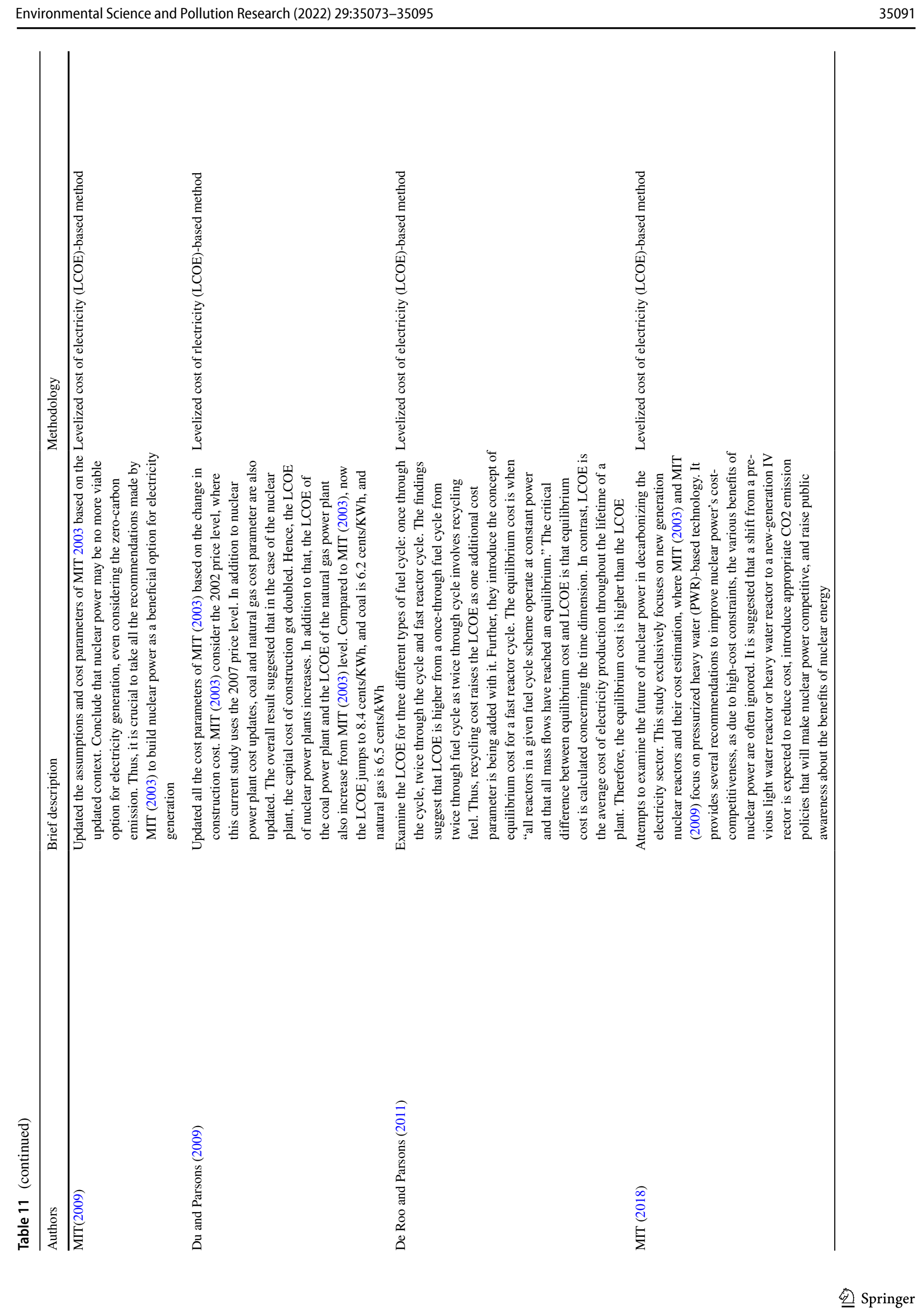




$$
\text { in }
$$




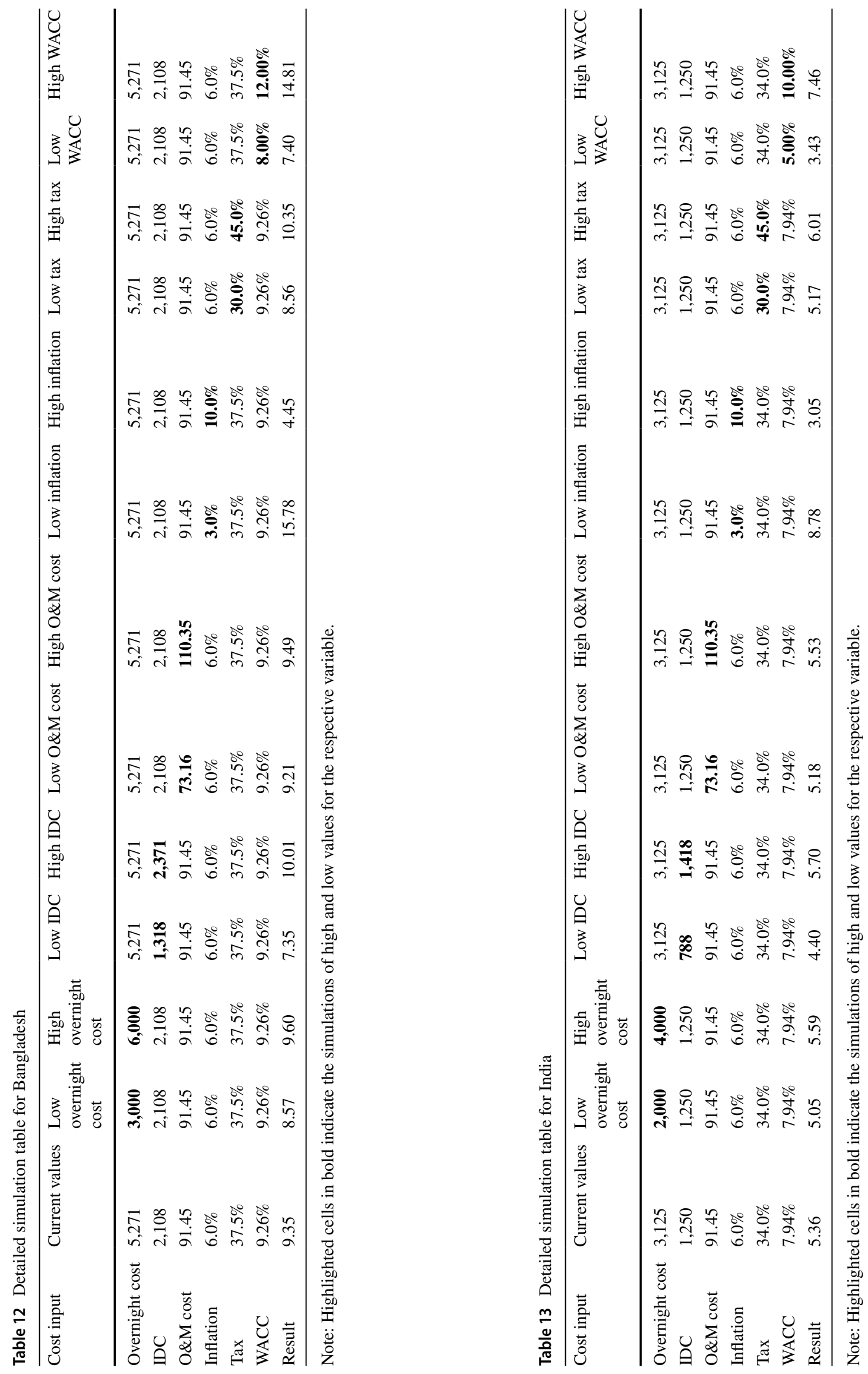


Supplementary Information The online version contains supplementary material available at https://doi.org/10.1007/s11356-021-18129-3.

Author contribution Gour Gobinda Goswami: Formulating idea, writing, reviewing, investigation, and editing, validation, supervision.

Umama Rahman: Methodology, levelized cost estimation, model, original draft preparation.

Mehdi Chowdhury: Literature review, editing, draft preparation, organization of the paper.

Funding This study is funded by North South University, Dhaka, Bangladesh, under its internal research grant for faculty members entitled "Conference, Travel, and Research Grant," Cycle: 2019-20.

Data availability The dataset is available at Harvard Dataverse: https:// doi.org/10.7910/DVN/UGJCUW

\section{Declarations}

Ethics approval Not applicable.

Consent to participate Not applicable.

Consent for publication Not applicable.

Conflict of Interest The authors declare no competing interests.

\section{References}

Abu-bakar SH, Bani NA, Munir AB, Imran A, Id K (2018) Nuclear Energy Development in Bangladesh : A Study of Opportunities and Challenges. Energies 1:1-15. https://doi.org/10.3390/en110 71672

Asian Development Bank (2020) Sector Assessment: Energy. Retrieved From: https://www.adb.org/sites/default/files/linked-documents/ LD-C-Energy-Operations-Assessment.pdf

Bangladesh Energy Regulatory Association (2016) Tariff for Roof Top Solar PV Electricity (Draft). Retrieved From: http://berc.portal. gov.bd/sites/default/files/files/berc.portal.gov.bd/page/a250b6fc_ 8bcf_4c96_bb20_3c3de230467a/berc_tariff_regulations_rooftof_ solar\%28draft $\% 29$.pdf

Bangladesh Power Development Board (2018) Annual Report 20182019.Retrieved From:https://www.bpdb.gov.bd/bpdb_new/resou rcefile/annualreports/annualreport_1574325376_Annual_Report_ 2018-19.pdf

Bharadwaj A, Krishnan LV, Rajgopal S (2008) Nuclear Power in India : The Road Ahead. Center for Study of Science, Technology and Policy (CSTEP)

Bharadwaj A, Tongia R, Arunachalam VS (2006) Whither Nuclear Power? Econ Pol Wkly 41(12):1203-1212

Davis L, Hausman C (2016) Market impacts of a nuclear power plant closure. Am Econ J Appl Econ 8(2):92-122. https://doi.org/10. 1257/app.20140473

GED. (2020a). 8th Five Year Plan July 2020-June 2025: Promoting Prosperity and Fostering Inclusiveness. General Economics Division, Bangladesh Planning Commission. December 2020

De Roo G, Parsons JE (2011) A methodology for calculating the levelized cost of electricity in nuclear power systems with fuel recycling. Energy Economics 33(5):826-839. https://doi.org/10. 1016/j.eneco.2011.01.008
Du Y, Parsons JE (2009) Update on the Cost of Nuclear Power. In Massachusetts Institute of Technology, Cambridge, MA.Working Paper 09-004, Center for Energy and Environmental Policy Research, Vol. 2009, Issue 75

Gilbert A, Sovacool BK, Johnstone P, Stirling A (2017) Cost overruns and financial risk in the construction of nuclear power reactors: A critical appraisal. Energy Policy 102:644-649. https://doi.org/ 10.1016/j.enpol.2016.04.001

Gupta K, Ripberger JT, Fox AS, Jenkins-smith HC, Silva CL (2021) The future of nuclear energy in India: Evidence from a nationwide survey. Energy Policy 156(May):112388. https://doi.org/10. 1016/j.enpol.2021.112388

Harris G, Heptonstall P, Gross R, Handley D (2013) Cost estimates for nuclear power in the UK. Energy Policy 62:431-442. https://doi. org/10.1016/j.enpol.2013.07.116

Hickey SM, Malkawi S, Khalil A (2021) Nuclear power in the Middle East: Financing and geopolitics in the state nuclear power programs of Turkey, Egypt, Jordan and the United Arab Emirates. Energy Res Soc Sci 74(15):101961

Ho S, Oshita T, Looi J, Leong A, Chuah A (2019) Exploring public perceptions of benefits and risks, trust, and acceptance of nuclear energy in Thailand and Vietnam: A qualitative approach. Energy Policy 127:259-268. https://doi.org/10.1016/j.enpol.2018.12.011

IAEA (2018) Climate change and Nuclear Power. Retrieved From: https://www.iaea.org/publications/13395/climate-change-andnuclear-power-2018

Islam MS, Bhuiyan TH (2020) Assessment of costs of nuclear power in Bangladesh. Nucl Energy Technol 6(3):181-194. https://doi. org/10.3897/nucet.6.54003

Islam S, Khan ZR (2017) A review of energy sector of Bangladesh. Energy Procedia 110(December 2016):611-618. https://doi.org/ 10.1016/j.egypro.2017.03.193

Kennedy D (2007) New Nuclear Power Generation in the UK : Cost Benefit Analysis. Energy Policy 35:3701-3716. https://doi.org/ 10.1016/j.enpol.2007.01.010

Kessides IN (2010) Nuclear power: Understanding the economic risks and uncertainties. Energy Policy 38(8):3849-3864. https://doi.org/ 10.1016/j.enpol.2010.03.005

Khondker BH, Hossain IH (2017) Financial and Economical Feasibility of Rooppur NPP, Energy and Power. Retrieved from: https:// epbd.com/view/details/article/MTU1NQ\%3D\%3D/title?q=Finan cial $+\% 26+$ Economic + Feasibility + of + Rooppur+NPP Last Accessed: $10 \mathrm{Jul} 2021$

Lehtonen M, Kojo M, Jartti T, Litmanen T, Kari M (2020)The roles of the state and social licence to operate? Lessons from nuclear waste management in Finland, France, and SwedenEnergy Res. Social Sci 61:101353. https://doi.org/10.1016/j.erss.2019.101353

Mahmood N, Wang Z, Zhang B (2020) The role of nuclear energy in the correction of environmental pollution : Evidence from Pakistan. Nucl Eng Technol 52(6):1327-1333. https://doi.org/10. 1016/j.net.2019.11.027

Ministry of Power (2016). Power System Master Plan 2016 (Issue September)

Ministry of Power (2019) Energy Scenario Bangladesh 2017-18. Retrieved From: http://www.hcu.org.bd/site/view/publications/-

MIT (Massachusetts Institute of Technology). (2003). The future of nuclear power worldwide. In Massachusetts Institute of Technology. Vol. 2, 4. https://doi.org/10.1504/AFP.2009.027869

MIT (Massachusetts Institute of Technology) (2009) The Future of Nuclear Power. In Massachusetts Institute of Technology. https:// doi.org/10.1016/B978-0-08-044489-5.X5000-1

MIT (Massachusetts Institute of Technology) (2018) The Future of Nuclear Energy in a Carbon-Constrained World. https://doi.org/ 10.1007/978-1-4615-1323-0_17 
Moazzem, K. G., \& Shibly, A. S. M. S. A. (2021). Power Sector in the 8th Five Year Plan: Reflection on Its Strategy and Initiatives. CPD Working Paper 138. Dhaka: Centre for Policy Dialogue (CPD)

Mostafa SMG, Singh JG, Masrur H, Ullah S (2017) A prospective model of Bangladesh electricity market (2016) International Conference on Innovations in Science, Engineering and Technology, ICISET. https://doi.org/10.1109/ICISET.2016.7856518

Muellner N, Arnold N, Gufler K, Kromp W, Renneberg W, Liebert W (2021) Energy Policy 1552(August 2020):112363

Ramana MV (2007) Economics of nuclear power: subsidies and competitiveness. Econ Polit Wkly 42(2):169-171. http://www.jstor. org/stable/4419139

Ramana MV, D'Sa A, Amulya KNR (2005) Economics of Nuclear Power from Heavy Water Reactors. JSTOR 2005:1-40

Ramana MV, Ahmad A (2020) Wishful thinking and real problems : Small modular reactors, planning constraints, and nuclear power in Jordan. Energy Policy 93(2016):236-245. https://doi.org/10. 1016/j.enpol.2016.03.012

Rothwell G (2006) A real options approach to evaluating new nuclear power plants. Energy J 27(1):37-53. https://doi.org/10.5547/ ISSN0195-6574-EJ-Vol27-No1-3

The World Bank (2019) World Development Indicator: Access to Electricity \% of Population (Data File). URL: http://data.worldbank. org/data-catalog/world-development-indicators

The World Bank (2020) World Development Indicators." URL: http:// data.worldbank.org/data-catalog/world-development-indicators. Accessed 22 December 2021

Singh A, Sharma S, Kalra MS (2018) Levelised Cost of Electricity for Nuclear Power Using Light Water Reactor Technology in India. Econ Political Week IIII(10):55-64
Wealer B, Kemfert C, Von Hirschhausen C (2018) Cost Estimates and Economics of Nuclear Power Plant Newbuild: Literature Survey and Some Modelling Analysis. September

World Nuclear Association (2008) The economics of nuclear power. Retrieved From: http://www.world-nuclear.org/uploadedfiles/org/ info/pdf/economicsnp.pdf

World Nuclear Association (2018) Country Profile Bangladesh. Retrieved from: http://www.world-nuclear.org/information-libra ry/country-profiles/countries-a. Accessed 22 December 2021

World Nuclear Association (2018b) Country Profile India. Retrieved from: https://world-nuclear.org/information-library/country-profi les/countries-g-n/india.aspx. Accessed 22 December 2021

World Nuclear Association (2020) COVID 19 Corona Virus and Nuclear Energy. Retrieved from: https://www.world-nuclear.org/ information-library/current-and-future-generation/covid-19-coron avirus-and-nuclear-energy.aspx. Accessed 22 December 2021

World Nuclear Association (2021) Nuclear Power in Jordan. Retrieved from: https://www.world-nuclear.org/information-library/countryprofiles/countries-g-n/jordan.aspx. Accessed 22 December 2021

Yildrium K, Gün M (2016) Public Attitude to Nuclear Energy from Climate Change and Energy Security Perspectives in Turkey. J Soc Admin Sci 3:141-160

Yu S, Yarlagadda B, Siegel JE, Zhou S, Kim S (2020) The role of nuclear in China's energy future: Insights from integrated assessment. Energy Policy 139(January):111344. https://doi.org/10. 1016/j.enpol.2020.111344

Publisher's Note Springer Nature remains neutral with regard to jurisdictional claims in published maps and institutional affiliations. 